\title{
Synthesis, Spectroscopic and DFT Characterization of 4/-(4-tert-Butylphenoxy)phthalocyanine Positional Isomers for Non-linear Optical Absorption
}

\author{
Denisha Gounden ${ }^{\mathrm{a}, \mathrm{b}}$, Grace N. Ngubeni ${ }^{\mathrm{b}}$, Marcel S. Louzada ${ }^{\mathrm{b}}$, Samson Khene, \\ Jonathan Britton ${ }^{\mathrm{b}}$ and Nolwazi Nombona, ${ }^{\mathrm{a}, \mathrm{t}}$ \\ ${ }^{a}$ School of Chemistry and Physics, University of KwaZulu-Natal, Durban, 4000, South Africa. \\ ${ }^{b}$ Department of Chemistry, Rhodes University, Grahamstown, 6140, South Africa. \\ Received 19 September 2016, revised 6 January 2017, accepted 8 January 2017.
}

\begin{abstract}
In this work the synthesis, spectral characterization and non-linear optical properties of metal-free $4 \beta$-(4-tert-butylphenoxy)phthalocyanine isomers are described and compared to the previously reported alpha derivative. The second-order nonlinear optical properties of the phthalocyanine isomers were investigated using the Z-scan technique and compared to the theoretical data obtained from density functional theory (DFT) and time dependent density functional theory (TD-DFT) calculations. Z-scan results indicated strong non-linear behaviour, revealing reverse saturable absorption (RSA) profiles for all four isomers. The experimental $\beta_{\exp }$ values showed the following trend: $C_{4 h}\left(9.31 \times 10^{-10} \mathrm{mMW}^{-1}\right)>\mathrm{D}_{2 \mathrm{~h}}\left(7.89 \times 10^{-10} \mathrm{mMW}^{-1}\right)>\mathrm{C}_{\mathrm{s}}(7.32 \times$ $\left.10^{-10} \mathrm{mMW}^{-1}\right)>\mathrm{C}_{2 \mathrm{v}}\left(1.77 \times 10^{-10} \mathrm{mMW}^{-1}\right)$. These results were similar to that obtained with the 4a-(4-tert-butylphenoxy)phthalocyanines as the $C_{2 v}$ and $C_{s}$ isomers were found to have the lowest $\beta_{\exp }$ values compared to other symmetries. The $4 \beta$-(4-tertbutylphenoxy)phthalocyanine $\mathrm{C}_{4 \mathrm{~h}}$ isomer was found to show better non-linear optical properties compared to all other isomers.
\end{abstract}

KEYWORDS

Phthalocyanine, non-linear optical absorption, density functional theory, magnetic circular dichroism.

\section{Introduction}

Since their discovery, phthalocyanines (Pcs) have been utilized in diverse applications which include photovoltaic energy conversion, ${ }_{1}^{1}$ photodynamic therapy, ${ }^{2}$ electrocatalysis ${ }^{3}$ and semiconductors. ${ }^{4}$ The use of Pcs for non-linear optical (NLO) absorption has found much interest in recent times ${ }^{5}$ due to its network of $\pi$-conjugated delocalized electrons. When interacting with strong electromagnetic fields such as laser radiation, the highly conjugated Pc structure promotes preferable polarizability and as well as fast distribution charge. ${ }^{6}$ Phthalocyanines are optical limiters that display reverse saturable absorption (RSA). ${ }^{7.8}$ This mechanism involves a sequential two photon absorption from the ground state $\left(\mathrm{S}_{0}\right)$ to a higher excited state $\left(\mathrm{S}_{1}\right)$. During excited state absorption, molecules are promoted from $S_{1}$ to a higher excited state $\left(\mathrm{S}_{\mathrm{n}}\right)$. Phthalocyanines are able to absorb intense light and upon their relaxation back to the ground state, they are able to intersystem cross from $S_{1}$ to the excited triplet $\left(\mathrm{T}_{1}\right)$ state. At this point the intense light would result in triplet-triplet absorption $\left(T_{1} \rightarrow T_{n}\right)$ making Pcs excellent optical limiters. ${ }^{9,10}$

It is recognized that the asymmetrical electronic structure of Pcs induced by the introduction and variation of peripheral substituents enhances NLO properties. When peripheral substituents are considered, a condensation reaction with a single phthalonitrile precursor can result in four constitutional isomers with $\mathrm{C}_{\mathrm{s}}, \mathrm{C}_{2 \mathrm{v}}, \mathrm{C}_{4 \mathrm{~h}}$ and $\mathrm{D}_{2 \mathrm{~h}}$ symmetries. ${ }^{6}$ Symmetry has been found to influence the NLO properties of Pcs. ${ }^{5}$ It has been reported that Pcs of lower symmetry show greater optical properties compared to Pcs of higher symmetry. ${ }^{11}$ For the purpose of this study, the isomers are labelled $\mathrm{C}_{\mathrm{s}}, \mathrm{C}_{2 \mathrm{v}}, \mathrm{C}_{4 \mathrm{~h}}$ and $\mathrm{D}_{2 \mathrm{~h}}$ to aid with the comparison to metallated phthalocyanine (MPc) complexes in * To whom correspondence should be addressed. E-mail: nombonan@ukzn.ac.za literature. ${ }^{12,13}$ In this work, the Z-scan technique combined with DFT calculations will be employed to investigate the NLO properties of the four constitutional isomers of $4 \beta$-(4-tert-butylphenoxy)phthalocyanine. Pure isomers may highlight interesting NLO properties which cannot be evaluated in a mixture of isomers.

\section{Experimental}

\subsection{Materials}

Acetic anhydride $\left(\mathrm{Ac}_{2} \mathrm{O}\right)$, acetone, $25 \%$ ammonia solution $\left(\mathrm{NH}_{4} \mathrm{OH}\right)$, formamide $\left(\mathrm{HCONH}_{2}\right)$, methanol $(\mathrm{MeOH})$ and potassium carbonate $\left(\mathrm{K}_{2} \mathrm{CO}_{3}\right)$ were obtained from Sigma-Aldrich or Merck. Dimethylformamide (DMF) was obtained from SigmaAldrich and dried using molecular sieves before use. Chloroform $\left(\mathrm{CHCl}_{3}\right)$, 1,8-diazabicyclo[5.4.0] undec-7-ene (DBU), 1-pentanol, high purity silica gel, silica gel TLC $60 \mathrm{~F}_{254}$ sheets, 4-tert-butylphenol and thionyl chloride $\left(\mathrm{SOCl}_{2}\right)$ were purchased from Sigma-Aldrich. 4-Nitrophthalonitrile was synthesized and purified according to literature. ${ }^{14}$

\subsection{Equipment}

Thin layer chromatography was done on silica gel $60 \mathrm{~F}_{254}$ sheets. Column chromatography was achieved on silica gel $60 \AA$ (63-200 $\mu \mathrm{m})$. UV-vis absorption spectra were recorded on a Shimadzu UV-2250 spectrophotometer. Fourier transform infrared (FT-IR) spectra were obtained using a Perkin-Elmer Spectrum 100 FT-IR Spectrometer, equipped with a diamond crystal ATR accessory. Magnetic circular dichroism (MCD) spectra were recorded on a Chirascan Plus spectropolarimeter fitted with a permanent magnet, producing a magnetic field of 
$1 \mathrm{~T}$ (tesla). Mass spectroscopy data were obtained using a Bruker AutoFLEX III smart-beam MALDI-TOF mass spectrometer, with an $\alpha$-cyano-4-hydroxycinnamic acid matrix in the positive ion mode. ${ }^{1} \mathrm{H}-\mathrm{NMR}$ spectra were recorded using a Bruker EMX 400 $\mathrm{MHz}$ NMR spectrometer. Fluorescence lifetimes were recorded using a time correlated single photon counting (TCSPC) technique perfomed on a FluoTime 300 Easy Tau spectrometer (PicoQuant $\mathrm{GmbH}$ ). A diode laser (LDH-P-670 with $20 \mathrm{MHz}$ repetition rate, 44 ps pulse width, Pico-Quant $\mathrm{GmbH}$ ) was used to excite the samples at $670 \mathrm{~nm}$. Fluorescence was detected with a Peltier cooled photomultiplier tube (PMT) (PMA-C 192-M, PicoQuant $\mathrm{GmBh}$ ). Decay curves measured at maximum emission. Lifetimes were obtained through the deconvolution of these curves using the $\mathrm{F}_{\mathrm{LUO}} \mathrm{F}_{\text {IT }}$ software program (PicoQuant $\mathrm{GmbH}$, Germany). The standard Z-scan technique was employed to evaluate the nonlinear optical properties of the $\mathrm{H}_{2} \mathrm{Pc}$ isomers. Phthalocyanines $\mathrm{T}_{1}-\mathrm{T}_{\mathrm{n}}$ absorption was achieved using a frequency-doubled Nd:YAG laser (Quanta-Ray, 1.5 J/10 ns FWHM pulse duration). The laser studies were performed using a near Gaussian transverse mode at $532 \mathrm{~nm}$, utilizing a repetition rate of $10 \mathrm{~Hz}$ and an energy range of $0.1 \mu \mathrm{J}-0.1 \mathrm{~mJ}$, monitored with an energy detector (Coherant J5-09). Mounting thermal nonlinearities were prevented by the low repetition rate of the laser. The laser beam was specifically filtered to limit the higher order modes and was focused using a $15 \mathrm{~cm}$ focal length lens. The stability of the system was achieved when there was no observable damage observed either between multiple runs or when the Pc samples were changed.

\subsection{Synthesis of 4-tert-Butylphenoxy Phthalocyanine $\left(\mathrm{tBuH}_{2} \mathrm{Pc}\right)$ Isomers}

The isomers were synthesized using a procedure previously described. ${ }^{15}$ Briefly, 4-(4-tert-butylphenoxy)phthalonitrile
( $0.75 \mathrm{~g}, 2.70 \mathrm{mmol})$ was transferred to a round-bottom flask to which pentanol $(6 \mathrm{~mL})$ was added. The mixture was refluxed with DBU (6 drops) under nitrogen for $5 \mathrm{~h}$. Thereafter, the green slurry was allowed to cool to room temperature and $\mathrm{MeOH}$ $(20 \mathrm{~mL})$ was used to precipitate the crude dark green product. Excess $\mathrm{MeOH}$ was added and the mixture was left to stir for $1 \mathrm{~h}$. The green solid was filtered under vacuum and left in air to dry overnight. The green product was loaded onto a silica gel column and the isomers were separated. The first three fractions (A, B and C) were eluted using DCM and each fraction was a different shade of green (Fig. 1). The fourth fraction (D) eluted as the darkest shade of green using $\mathrm{MeOH}$ and DCM (v/v; $1: 5)$ as the solvent system. Figure 2 shows the four positional isomers $\left(\mathrm{C}_{4 \mathrm{~h}}, \mathrm{D}_{2 \mathrm{~h}}, \mathrm{C}_{\mathrm{s}}\right.$ and $\left.\mathrm{C}_{2 \mathrm{v}}\right)$ of $4 \beta$-(4-tert-butylphenoxy)phthalocyanines.

Fraction A: Yield: $100 \mathrm{mg}(10 \%)$. UV-vis (DCM): $\lambda_{\max } \mathrm{nm}(\log \varepsilon)$ : 702 (5.02); 667 (4.97); 641 (4.58); 608 (4.39); 403 (4.35); 339 (4.39). IR $\left(v_{\max } \mathrm{cm}^{-1}\right): 1236(\mathrm{C}-\mathrm{O}-\mathrm{C}) ; 1367\left(\mathrm{CH}_{3}\right) ; 1465,1509,1605(\mathrm{C}=\mathrm{C})$;

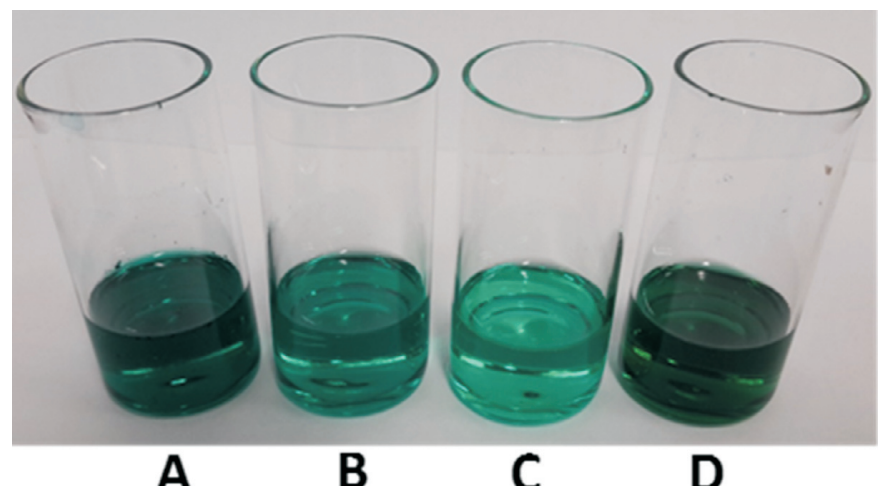

Figure 1 Varying colours observed for the four fractions in DCM.

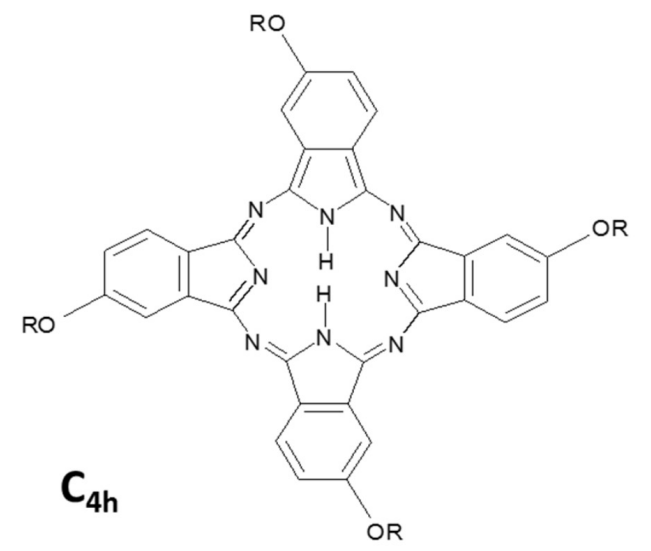

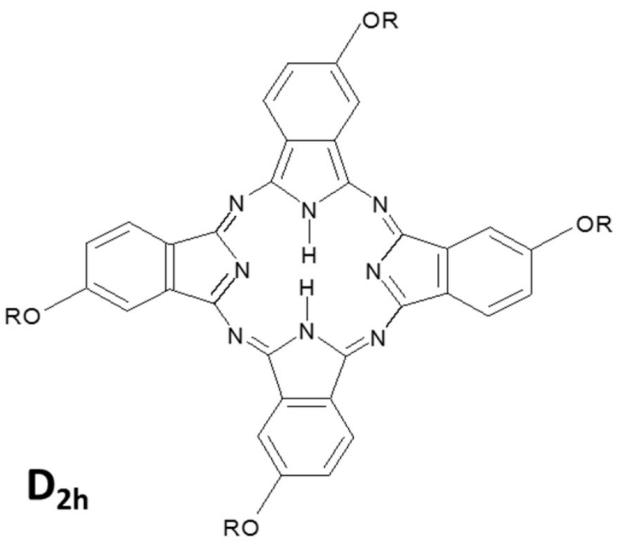

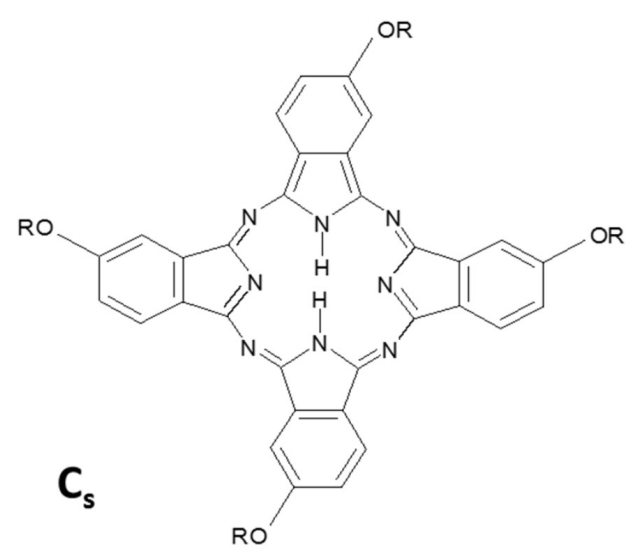

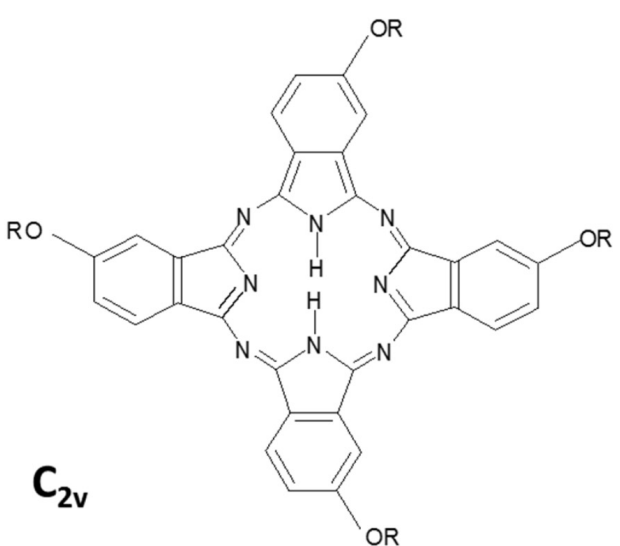<smiles>Cc1ccc(C(C)(C)C)cc1</smiles>

Figure 2 The four constitutional isomers of $4 \beta$-(4-tert-butylphenoxy)phthalocyanine. 
2853, 2922, 2955 (-C-H); 3042, 3294 (=C-H). MS (MALDI-TOF): Calculated: $1107 \mathrm{~m} / z$. Found: $1109 \mathrm{~m} / \mathrm{z} .{ }^{1} \mathrm{H}$ NMR $\left(\mathrm{CDCl}_{3}\right): \delta \mathrm{ppm}$ 7.9-7.5 (28 - H, m, Pc; Ar-H); 1.5 (36-H, s, Bu $\left.{ }^{\mathrm{t}}\right)$

Fraction B: Yield: $200 \mathrm{mg}(20 \%)$. UV-vis (DCM): $\lambda_{\max } \mathrm{nm}(\log \varepsilon)$ : 702 (4.69); 667 (4.63); 641(4.20); 607(4.01); 401 (4.01); 340(4.38). IR $\left(v_{\max } \mathrm{cm}^{-1}\right): 1234(\mathrm{C}-\mathrm{O}-\mathrm{C}) ; 1363\left(\mathrm{CH}_{3}\right) ; 1465,1506,1602(\mathrm{C}=\mathrm{C})$; 2853, 2922, 2955 (-C-H); 3043, 3287 (=C-H). MS (MALDI-TOF): Calculated: $1107 \mathrm{~m} / z$. Found: $1109 \mathrm{~m} / \mathrm{z} .{ }^{1} \mathrm{H}$ NMR $\left(\mathrm{CDCl}_{3}\right): \delta \mathrm{ppm}$ 7.9-7.5 (28 - H, m, Pc; Ar-H); 1-1.5 (36-H, s, Bu'

Fraction C: Yield: $150 \mathrm{mg}(15 \%)$. UV-vis (DCM): $\lambda_{\max } \mathrm{nm}(\log \varepsilon)$ : 702 (4.98); 667 (4.92); 640 (4.53); 608 (4.34); 400 (4.35); 340 (4.70). IR $\left(v_{\max } \mathrm{cm}^{-1}\right): 1238(\mathrm{C}-\mathrm{O}-\mathrm{C}) ; 1368\left(\mathrm{CH}_{3}\right) ; 1465,1507,1604(\mathrm{C}=\mathrm{C})$; 2853, 2923, 2955 (-C-H), 3047, 3295 (=C-H). MS (MALDI-TOF): Calculated: $1107 \mathrm{~m} / z$. Found: $1109 \mathrm{~m} / \mathrm{z} .{ }^{1} \mathrm{H} \mathrm{NMR}\left(\mathrm{CDCl}_{3}\right): \delta \mathrm{ppm}$ 7.9-7.5 (28 - H, m, Pc; Ar-H); 1.5 (36-H, s, Bu $\left.{ }^{t}\right)$

Fraction D: Yield: $60 \mathrm{mg}(6 \%)$. UV-vis (DCM): $\lambda_{\max } \mathrm{nm}(\log \varepsilon)$ : 705 (4.86); 673 (4.82); 649 (4.61); 621 (4.47); 391 (4.54); 338(4.84). IR $\left(v_{\max } \mathrm{cm}^{-1}\right): 1231(\mathrm{C}-\mathrm{O}-\mathrm{C}) ; 1366\left(\mathrm{CH}_{3}\right) ; 1474,1505,1601(\mathrm{C}=\mathrm{C})$; 2851, 2921, 2955 (-C-H); 3041, 3286 (=C-H). MS (MALDI-TOF): Calculated: $1107 \mathrm{~m} / z$. Found: $1109 \mathrm{~m} / \mathrm{z} .{ }^{1} \mathrm{H} \mathrm{NMR}\left(\mathrm{CDCl}_{3}\right): \delta \mathrm{ppm}$ 7.9-7.5 (28 - H, m, Pc; Ar-H); 1.5 (36-H, s, Bu $\left.{ }^{t}\right)$

\subsection{Computational Details}

The geometry optimizations of the $\mathrm{H}_{2} \mathrm{Pc}$ isomers were carried out by means of the B3LYP density functional with the 6-31G(d) basis set as applied in the Gaussian 03 software. The B3LYP exchange-correlation density functional uses Becke's method via his B88 exchange functional and the Lee-Yang Parr correlation functional, which incorporates a combination of semi-empirical Hartree-Fock and DFT exchange. ${ }^{16-19}$ The Gaussview 4.1 interface was employed for the visualizations of molecular orbitals (MOs) as well as other relevant properties. ${ }^{20}$ An identical method was used to perform single point energy calculations in order to determine the NLO response $(\beta)$ in accordance to literature techniques ${ }^{21}$ using $\mathrm{H}_{2}(\mathrm{OH})_{4} \mathrm{Pc}$ as the standard compound. With $\mathrm{H}_{2}(\mathrm{OH})_{4} \mathrm{Pc}$ used as the model compound, TD-DFT calculations were carried out using the B3LYP functional of the Gaussian 09 software package with $6-31 \mathrm{G}(\mathrm{d})$ basis set. $^{22}$

\subsubsection{Second-order NLO Optics Calculations}

The equation used to calculate the magnitude of the first hyperpolarizability of a $3 \times 3 \times 3$ matrix with 10 components (Equation (S1) in Supplementary Material) was determined by performing DFT calculations according to literature. ${ }^{21}$

$$
\begin{aligned}
\beta_{e f f}= & {\left[\left(\beta_{x x x}+\beta_{x y y}+\beta_{x z z}\right)^{2}+\left(\beta_{y y y}+\beta_{y z z}+\beta_{y x x}\right)^{2}+\right.} \\
& \left.\left(\beta_{z z z}+\beta_{z x x}+\beta_{z y y}\right)^{2}\right]^{\frac{1}{2}}
\end{aligned}
$$

Since the $\beta_{i j k}$ values provided by the Gaussian 03 software are reported in Debye, $\AA^{2}$, the calculated $\beta_{\text {eff }}$ values were converted to electrostatic units (esu), $\left(1 \AA^{2}=1 \times 10^{-30} \mathrm{esu}\right)$.

\subsubsection{Octupolar and Dipolar Contribution Calculations}

DFT calculation of hyper-Rayleigh Scattering (HRS) response coefficient $\left(\beta_{\text {HRS }}\right)$ was carried out in order to calculate the first static hyperpolarizability (second-order hyperpolarizability), following literature method $\mathrm{s}^{23-26}$ The advantage of this method is that octupolar and dipolar second-order NLO contributions are theoretically separated. The values of both dipolar $\left(\beta_{I=1}\right)$ and octupolar $\left(\beta_{I=3}\right)$ are known to be significantly influenced by the number of electrons in the system. ${ }^{23}$ Due to symmetry constraints there is no permanent dipole moment for octupolar molecules, ${ }^{25}$ hence octupolar molecules present an isotropic $\beta$ tensor.
It is to be noted that the equations presented below are only valid in the off-resonance region. The following equations can be used to calculate the $\left(\beta_{\mathrm{HRS}}\right)$ response; however, reference [21] method as indicated above was used to calculate the secondorder nonlinear coefficient. In Equation (2), $\left\langle\beta_{\mathrm{zzz}}^{2}\right\rangle$ and $\left\langle\beta_{\mathrm{ZXX}}^{2}\right\rangle$ are the orientation average of the molecular $\beta$ tensor components.

$\beta_{H R S}(-2 \omega ; \omega, \omega)=\left(\left\langle\beta_{Z Z Z}^{2}\right\rangle+\left(\left\langle\beta_{Z X X}^{2}\right\rangle\right)^{1 / 2}\right.$

The molecular $\beta$ tensor were calculated using Equations (3) and $(4)^{23}$ :

$$
\begin{aligned}
\left\langle\beta_{Z Z Z}^{2}\right\rangle= & \frac{1}{7} \sum_{\zeta}^{x, y, z} \beta_{\zeta \zeta \zeta}^{2}+\frac{6}{35} \sum_{\zeta \neq \eta}^{x, y, z} \beta_{\zeta \zeta \zeta} \beta_{\zeta \eta \eta}+\frac{9}{35} \sum_{\zeta \neq \eta}^{x, y, z} \beta_{\eta \zeta \zeta}^{2}+ \\
& \frac{3}{35} \sum_{\zeta \neq \eta \neq \xi}^{x, y, z} \beta_{\eta \zeta \zeta} \beta_{\eta \zeta \xi}+\frac{2}{3} \sum_{\zeta \neq \eta \neq \xi}^{x, y, z} \beta_{\zeta \eta \xi}^{2} \\
\left\langle\beta_{Z X X}^{2}\right\rangle= & \frac{1}{35} \sum_{\zeta}^{x, y, z} \beta_{\zeta \zeta \zeta}^{2}-\frac{2}{105} \sum_{\zeta \neq \eta}^{x, y, z} \beta_{\zeta \zeta \zeta} \beta_{\zeta \eta \eta}+\frac{11}{105} \sum_{\zeta \neq \eta}^{x, y, z} \beta_{\eta \zeta \zeta}^{2}- \\
& \frac{1}{105} \sum_{\zeta \neq \eta \neq \xi}^{x, y, z} \beta_{\eta \zeta \zeta} \beta_{\eta \zeta \zeta}+\frac{4}{105} \sum_{\zeta \neq \eta \neq \xi}^{x, y, z} \beta_{\zeta \eta \xi}^{2}
\end{aligned}
$$

Furthermore, the molecular geometric information is given by the depolarization ratio (DR), which is expressed by DR = $\left\langle\beta_{\mathrm{ZZZ}}^{2}\right\rangle /\left\langle\beta_{\mathrm{ZXX}}^{2}\right\rangle$. The nature of the symmetric Rank-3 $\beta$ tensor is further clarified by decomposing $\left\langle\beta_{\text {HRS }}^{2}\right\rangle$ as the sum of the dipolar $\left(\beta_{I=1}\right)$ and octupolar $\left(\beta_{I=3}\right)$ tensorial components, ${ }^{25}$ which are expressed as Equations (6) and (7):

$$
\begin{aligned}
\beta_{H R S}= & \sqrt{\left(\beta_{H R S}^{2}\right)}=\sqrt{\frac{10}{45}\left|\beta_{J=1}\right|^{2}+\frac{10}{105}\left|\beta_{J=3}\right|^{2}} \\
\left|\beta_{J=1}\right|^{2}= & \frac{3}{5} \sum_{\zeta}^{x, y, z} \beta_{\zeta \zeta \zeta}^{2}+\frac{6}{5} \sum_{\zeta \neq \eta}^{x, y, z} \beta_{\zeta \zeta \zeta} \beta_{\zeta \eta \eta}+\frac{3}{5} \sum_{\zeta \neq \eta}^{x, y, z} \beta_{\eta \zeta \zeta}^{2}+ \\
& \frac{3}{5} \sum_{\zeta \neq \eta \neq \xi}^{x, y, z} \beta_{\eta \zeta \zeta} \beta_{\eta \xi \xi} \\
\left|\beta_{J=3}\right|^{2}= & \frac{2}{5} \sum_{\zeta}^{x, y, z} \beta_{\zeta \zeta \zeta}^{2}-\frac{6}{5} \sum_{\zeta \neq \eta}^{x, y, z} \beta_{\zeta \zeta \zeta} \beta_{\zeta \eta \eta}+\frac{12}{5} \sum_{\zeta \neq \eta}^{x, y, z} \beta_{\eta \zeta \zeta}^{2}- \\
& \frac{3}{5} \sum_{\zeta \neq \eta \neq \xi}^{x, y, z} \beta_{\eta \zeta \zeta} \beta_{\eta \xi \xi}+\sum_{\zeta \neq \eta \neq \xi}^{x, y, z} \beta_{\zeta \eta \xi}^{2}
\end{aligned}
$$

The ratio of octupolar $\left[\phi_{I=3}=\rho /(1+\rho)\right]$ and dipolar $\left[\phi_{J=1}=1 /(1\right.$ $+\rho)$ ] contribution to the hyperpolarizability tensor is determined by substituting the nonlinear anisotropy parameter $\rho=\left|\beta_{J=3}\right| /\left|\beta_{J=1}\right|$. The nonlinear anisotropy parameter values run from 0 (pure dipole) to $\infty$ (pure octupole).

The theoretical normalized HRS intensity $\left(I_{\psi \nu}^{2 \omega}\right)$ is determined by using Bersohn's expression, ${ }^{25}$ Equation (8), which assumes a general elliptically polarized incident light propagating along the $X$ direction. Equation (8) further assumes that the intensity of the harmonic light is scattered at $90^{\circ}$ along the $Y$ direction and the vertically $(\mathrm{V})$ polarized light along the $\mathrm{Z}$ axis.

$I_{\Psi V}^{2 \omega} \propto\left\langle\beta_{Z X X}^{2}\right\rangle \cos ^{4} \Psi+\left\langle\beta_{Z Z Z}^{2}\right\rangle \sin ^{4} \Psi+\sin ^{2} \Psi \cos ^{2} \Psi \times$

$\left\langle\left(\beta_{Z X Z}+\beta_{Z Z X}\right)^{2}-2 \beta_{Z Z Z} \beta_{Z X X}\right\rangle$

The orientational averages $\left\langle\left(\beta_{\mathrm{zxz}}+\beta_{\mathrm{zzx}}\right)^{2}-2 \beta_{\mathrm{zzz}} \beta_{\mathrm{zxx}}\right\rangle$ in Equation (8) is expressed as Equation (9):

$$
\begin{aligned}
&\left\langle\left(\beta_{Z X Z}+\beta_{Z Z X}\right)^{2}-2 \beta_{Z Z Z} \beta_{Z X X}\right\rangle=7\left\langle\beta_{Z X X}^{2}\right\rangle-\left\langle\beta_{Z Z Z}^{2}\right\rangle \\
&=\frac{2}{35} \sum_{\zeta}^{x, y, z} \beta_{\zeta \zeta \zeta}^{2}-\frac{32}{105} \sum_{\zeta \neq \eta}^{x, y, z} \beta_{\zeta \zeta \zeta} \beta_{\zeta \eta \eta}+\frac{10}{21} \sum_{\zeta \neq \eta}^{x, y, z} \beta_{\eta \zeta \zeta}^{2}- \\
& \frac{16}{105} \sum_{\zeta \neq \eta \neq \xi}^{x, y, z} \beta_{\eta \zeta \zeta} \beta_{\eta \zeta \xi}+\frac{22}{105} \sum_{\zeta \neq \eta \neq \xi}^{x, y, Z} \beta_{\zeta \eta \xi}^{2}
\end{aligned}
$$




\section{Results and Discussion}

3.1. Synthesis and Characterization $4 \beta-(4-t e r t-B u t y l-$ phenoxy)phthalocyanines $\left(\mathrm{tBuH}_{2} \mathrm{Pc}\right)$ Isomers

The 4-nitrophthalonitrile was converted to the 4-tert-butyl phenoxy phthalonitrile through a base catalyzed displacement of the nitro functional group by 4-tert-butyl phenol. Cyclotetramerization of the 4-tert-butyl phenoxy phthalonitrile yielded the corresponding $\mathrm{tBuH}_{2} \mathrm{Pc}$ isomers. The $\mathrm{tBuH}_{2} \mathrm{Pc}$ was soluble in organic solvents such as chloroform $\left(\mathrm{CHCl}_{3}\right), \mathrm{DCM}$ and THF. The dark green complex underwent purification and isomer separation by column chromatography.

The C-O-C vibration at $1248 \mathrm{~cm}^{-1}$ verified the formation of the 4-(4-tert-butylphenoxy)phthalonitrile. Conversion into the corresponding $\mathrm{tBuH}_{2} \mathrm{Pc}$ was indicated by the loss of the intense $-\mathrm{CN}$ stretch at $2232 \mathrm{~cm}^{-1}$. MALDI-TOF spectral data revealed molecular ion peaks at $1109 \mathrm{~m} / \mathrm{z}$ for all isomers. This mass differs from the expected mass by 2 protons due to possible protonation of the nitrogen atoms of the Pc. This mass confirms the proposed
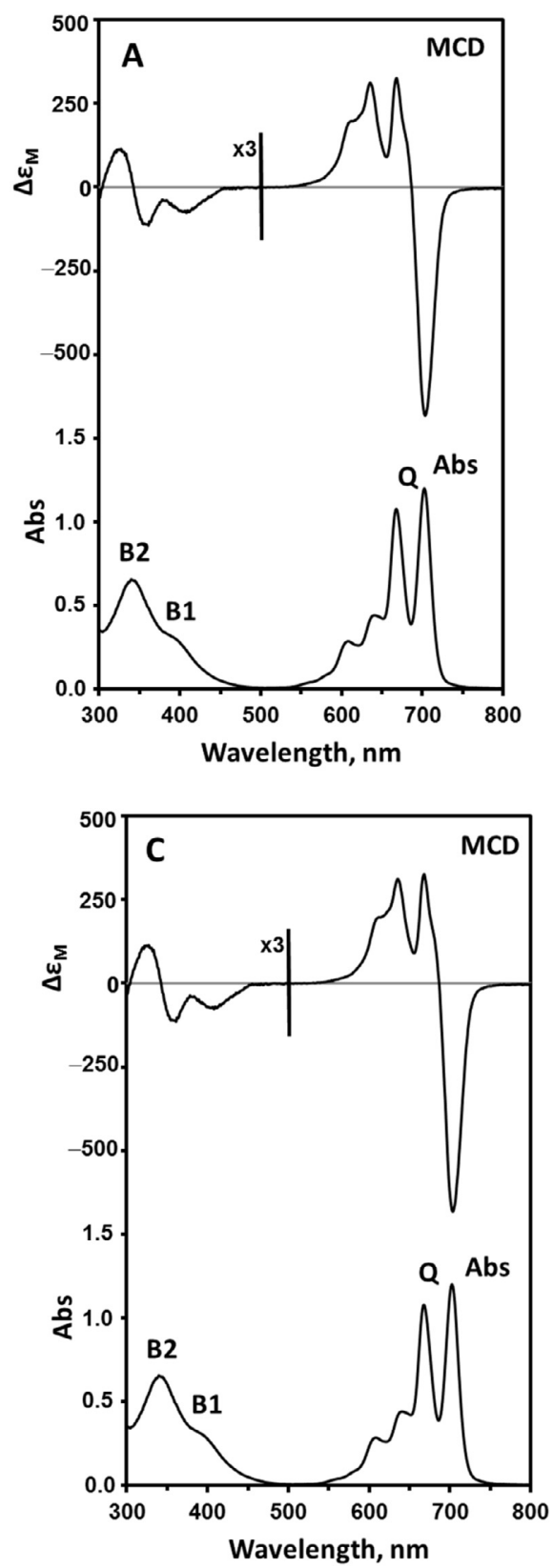

Pc structure. Ring protonation is common during the ionization process of Pcs. ${ }^{27}$ The ${ }^{1} \mathrm{H}$ NMR of the isomers in $\mathrm{CDCl}_{3}$ showed similar and broad aromatic peaks between 7 and $8 \mathrm{ppm}$ and the integration of the peaks gave a total of 28 protons. The extended delocalized aromatic $\pi$ electron cloud causes extensive stacking of the planar Pc macrocycles. ${ }^{28}$ This aggregation significantly affects proton chemical shifts and results in weak and broad peaks. ${ }^{29}$ Differentiation between the protons was difficult as the 4-tert butyl aromatic protons were deshielded such that the signals overlapped with those of the Pc ring. The internal protons which are usually observed between 2 and $6 \mathrm{ppm}$, were not observed for all isomers as the localization of these chemical shifts are also highly influenced by aggregation.

\subsection{Electronic Absorption Spectroscopy, Magnetic Circular} Dichroism (MCD) Spectroscopy and TD-DFT Calculations

UV-vis spectra obtained were typical for unmetallated Pcs and all fractions showed similar absorption (Fig. 3). The spectra showed a split $Q$ band in the red region and the $B$ band in the
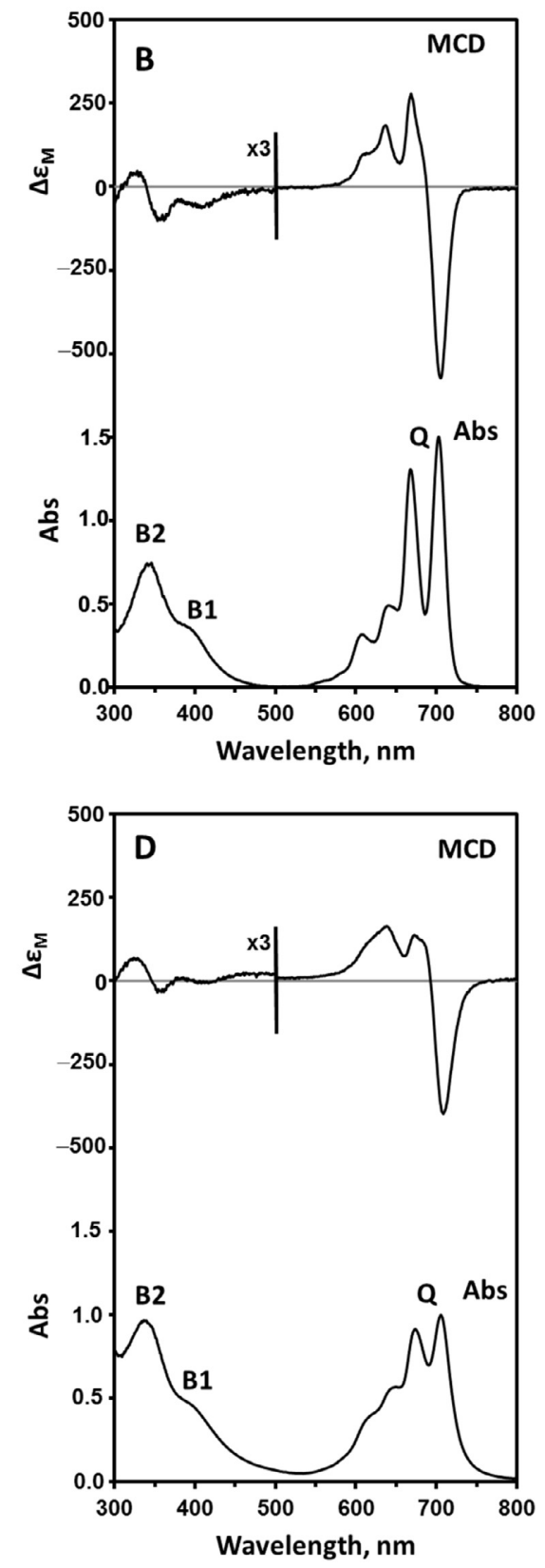

Figure 3 MCD spectra (above) and absorption spectra (below) of Fractions A-D. 
blue region. The $\mathrm{B}$ and $\mathrm{Q}$ bands are characteristic to Gouterman's 4-orbital mode ${ }^{30}$ for $\mathrm{D}_{4 \mathrm{~h}}$ symmetry of a metal porphyrin. The $\mathrm{Q}$ band observed in the 667-705 $\mathrm{nm}$ region for the isomers are associated with $x / y$-polarization. This is linked primarily to excitation from the highest occupied molecular orbital (HOMO, $\mathrm{a}_{1 \mathrm{u}}$ ) to the lowest unoccupied molecular orbital (LUMO, $\mathrm{e}_{\mathrm{g}}$ ). The B bands (assigned B1 and B2) correspond to transitions from the $\mathrm{a}_{2 \mathrm{u}}$ and $\mathrm{b}_{2 \mathrm{u}}$ to the $\mathrm{e}_{\mathrm{g}}$ level. ${ }^{31}$ The $\mathrm{Q}$ bands were blue shifted compared to the $\alpha$ derivative. ${ }^{13}$ This shift is as a result of an increase in the HOMO-LUMO energy gap which is highly influenced by electron density. The electron-withdrawing nature of the substituents at the alpha position results in the lowering of the energy gap.

Magnetic circular dichroism (MCD) was used to obtain information regarding the degeneracy of ground and excited electronic states of the isomers. The absorption and MCD spectra are shown in Fig. 3 for Fractions A and D. Fraction A displayed similar spectral properties as Fractions B and C. The $Q$ band of Fraction D displays a slight deviation showing less splitting, attributed to lower symmetry than the other isomers. The MCD spectra show the $\mathrm{B}_{0}$ term, demonstrating that the $\mathrm{B} 1$ and $\mathrm{B} 2$ bands appear in the $300-400 \mathrm{~nm}$ region. $^{32}$ The absorption between 400 and $470 \mathrm{~nm}$ was attributed to the $\mathrm{n} \rightarrow \pi^{*}$ transitions. This transition occurs either as a result of the lone pairs on the outer oxygen atoms $\mathrm{s}^{13,33}$ or the destabilization of the $\mathrm{sp}^{3}$ hybridized oxygen atoms on the $\pi$-MOs. ${ }^{34}$ Figure 4 supports the $n \rightarrow \pi^{*}$ transitions being due to the delocalization of molecular orbitals on the oxygen atom for the four regio isomers. When comparing the optimized energies of the isomers, no significant difference was observed. This indicates that changing the position of the substituents does not change the minimum energy of this compound.

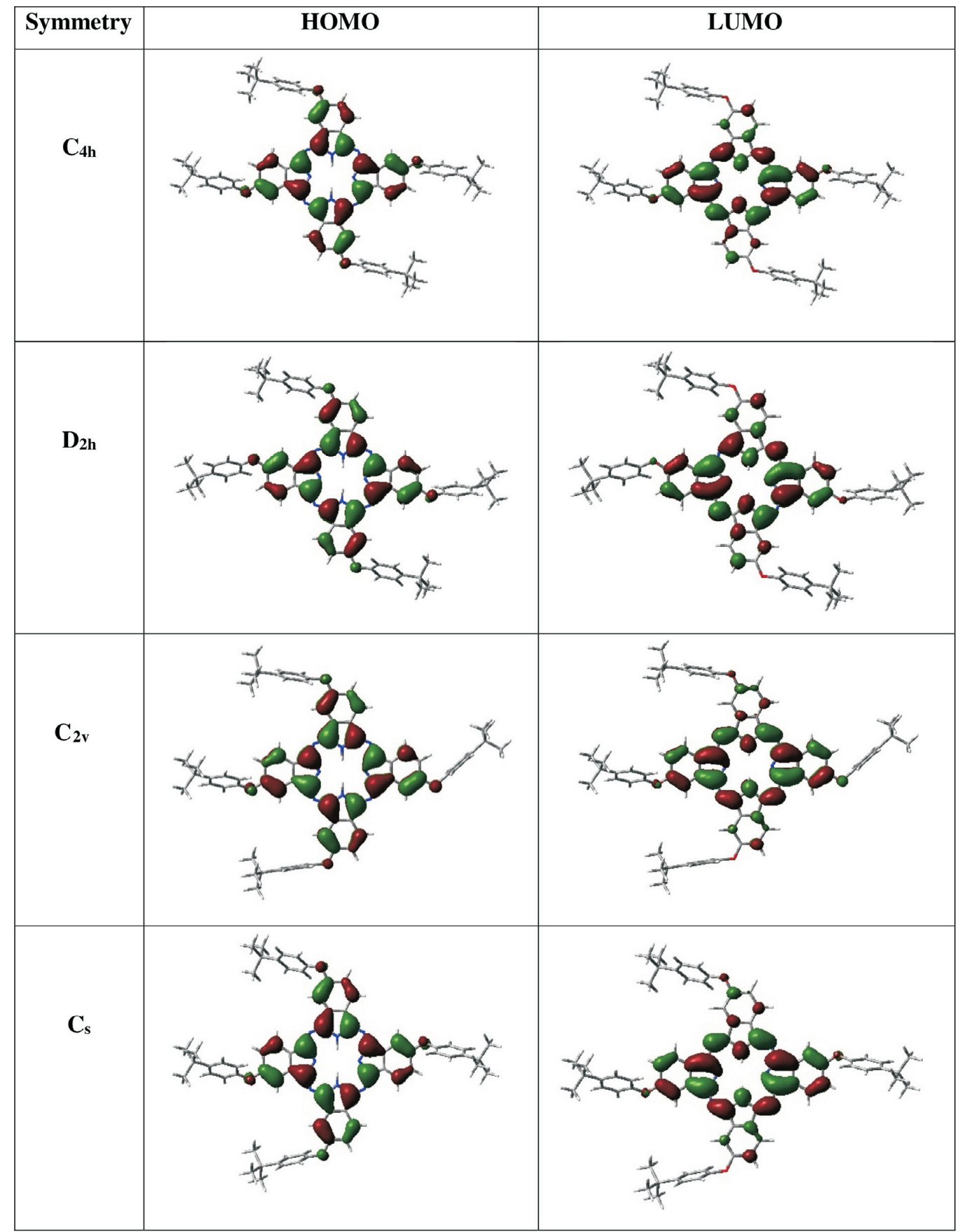

Figure $4 \mathrm{HOMO}$ and LUMO molecular orbital distribution of regio isomers. 
The curves observed in the $650-700 \mathrm{~nm}$ region of the MCD spectra each have a centre essentially at the same wavelength as that of the maximum absorption. A comparison of the UV-vis and MCD spectra lead to an unambiguous assignment of the $Q$ bands for the fractions displayed in Table 1.

The TD-DFT results (Fig. 5) were identical for the isomers and were consistent with the experimental absorption spectra. The assignment of the $\mathrm{Q}$ and $\mathrm{B}$ bands are based on the allowed transitions between the molecular orbitals, which does not account for the intensity of the peaks. The $Q$ band arises from the $\mathrm{a}_{1 \mathrm{u}}$ (HOMO) to the $e_{g}$ (LUMO) and the $B$ band from $a_{2 u}$ and $b_{2 u}$ orbitals to the $\mathrm{e}_{\mathrm{g}}$ orbital. The point groups of unmetallated $\mathrm{Pc}$ isomers lack a four-fold symmetry. This property results in the $Q$ band being split into $x$ - and $y$-polarized bands as observed in the UV-vis spectra. The TD-DFT calculations were performed under vacuum conditions and the discrepancy in peak intensity between the experimental and theoretical data could be due to solvent effects. ${ }^{35}$

\subsection{Fluorescence Spectra}

The excitation spectra (Fig. 6) for Fractions A-C were identical to their respective absorption spectra. The excitation spectra of Fraction D differed from its absorption spectra with changes to the position and shape of the Q band. This suggests a slight change of symmetry upon excitation of the Fraction D isomer.

Table $1 \mathrm{Q}$ bands from MCD and UV-vis spectroscopy.

\begin{tabular}{ccc}
\hline Fractions & $\mathrm{MCD} / \mathrm{nm}$ & UV-vis/nm \\
& $\mathrm{Q}$ & $\mathrm{Q}$ \\
\hline A & $703 ; 668$ & $702 ; 667$ \\
B & $703 ; 668$ & $702 ; 667$ \\
C & $703 ; 668$ & $702 ; 667$ \\
D & $708 ; 672$ & $705 ; 673$ \\
\hline
\end{tabular}
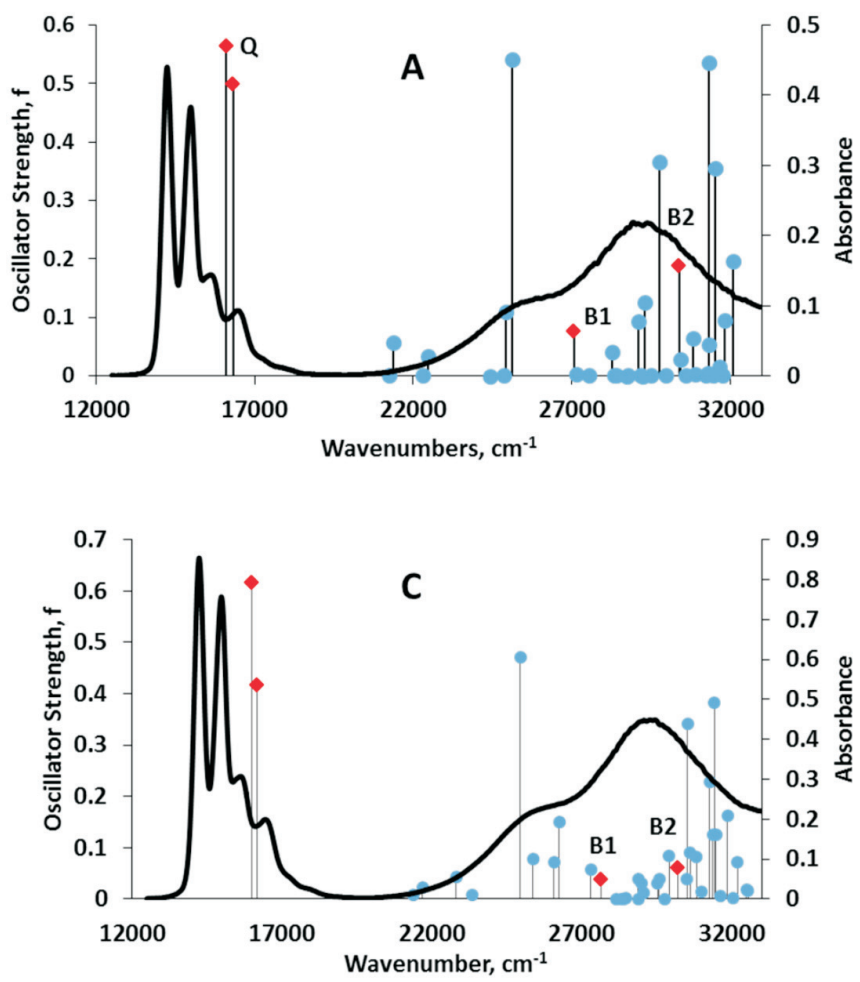

The differences that are observed in the absorbance and excitation spectra in Fraction D are also attributed to aggregation in the latter. Since aggregates do not fluoresce, a similar behaviour is not seen in the excitation spectrum. There were no symmetry changes observed on the emission spectra of the tBuH2Pcs.

Table 2 shows the excitation and emission spectra, fluorescence lifetime $(\tau)$ and anisotropy rotational correlation time $(\phi)$ of the isomers. The fluorescence lifetimes of the isomers were measured and ranged between 5.5 and $5.8 \mathrm{~ns}$, within the typical range observed for monomeric Pc compounds. ${ }^{13,36,37}$ The fluorescence lifetimes observed for the $\beta$ derivative are found to be greater than those observed for the $\alpha$ derivative. The chi-square values were between 0.99 and 1.01, describing a good fit of the mono-exponential decay curves to the experimental data. The rotational correlation time measures the time taken for each of the four isomers to rotate one radian. Fractions A-D measured $0.42,0.43,0.40$ and 0.49 correlation times (ns) respectively. The Fraction D appears to have a greater correlation time than the other isomers. This trend has been reported in a similar study of isomers by Ngubeni et al. ${ }^{13}$ Rotational correlation times are influenced by solvent viscosity, the shape and size of the molecule. ${ }^{38}$ The isomers showed differences in rotational correlation times. Since the experiments were carried out in DCM and the isomers have the same molecular weight, this difference can then be associated with the orientation of the isomer structures. Fraction D showed the largest correlation time indicating that this isomer may experience larger solvent resistance during its rotations. ${ }^{13}$ This also suggests that the molecular structure of the isomer affects $\tau$, as it exhibits a shorter $\tau$ than the other isomers. Typical correlation times for Pcs are within the $0.3-4$ ns range. ${ }^{39}$ The molecular volume of each isomer was determined using the following Equation (10) ${ }^{40}$ :

$\phi=\frac{\eta v}{k T}$
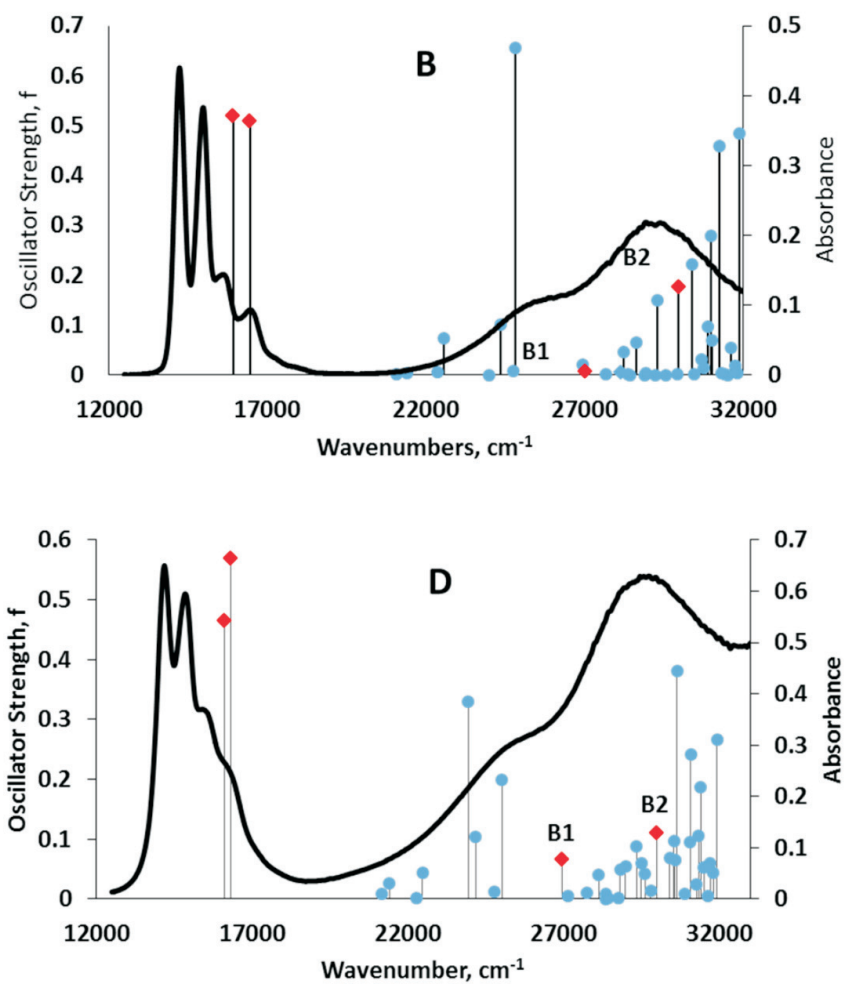

Figure 5 Calculated and experimental (solid vertical line) absorption spectra of 4 $\beta$-(4-tert-butylphenoxy)phthalocyanine positional isomers are plotted against the primary and secondary axes, respectively. Circles represent the calculated spectral bands whereas red diamonds show the main Q, B1 and $\mathrm{B} 2$ bands. 

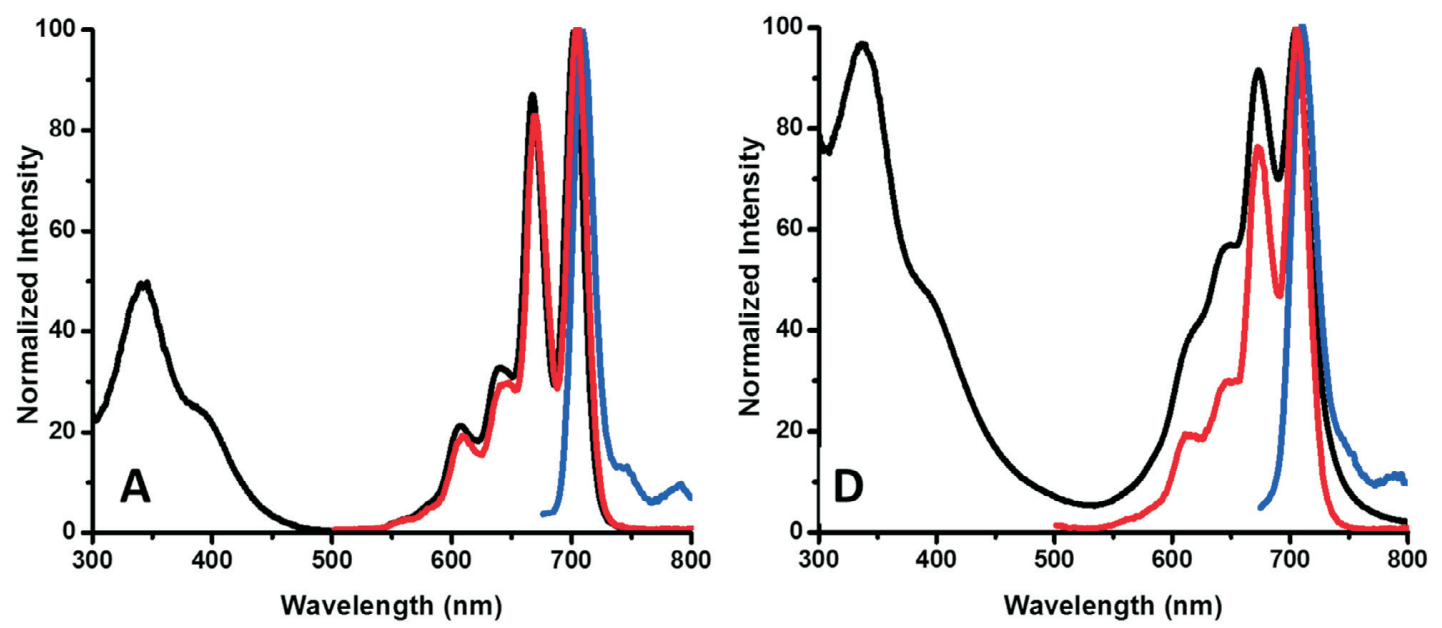

Figure 6 Absorption (black), excitation (red) and emission (blue) spectra for Fraction A (left) and Fraction D (right).

Table $2 \mathrm{Q}$ band maxima $\left(\lambda_{\max }\right)$ in absorbance, fluorescence excitation and emission, fluorescence lifetime $(\tau)$, anisotropy rotational correlation time $(\phi)$ and molecular volumes $\left(\mathrm{V}_{\mathrm{m}}\right)$ of the isomers.

\begin{tabular}{|c|c|c|c|c|c|c|}
\hline \multirow[t]{2}{*}{ Fraction } & \multicolumn{3}{|c|}{$\lambda_{\max } / \mathrm{nm}$} & \multirow[t]{2}{*}{$\tau / \mathrm{ns}$} & \multirow[t]{2}{*}{$\phi / \mathrm{ns}$} & \multirow{2}{*}{$\begin{array}{c}\mathrm{V}_{\mathrm{m}} \\
/ \times 10^{-27} \mathrm{~m}^{3}\end{array}$} \\
\hline & Absorbance & Emission & Excitation & & & \\
\hline A & $702 ; 667$ & 708 & 702 & $5.82 \pm 0.0267$ & $0.428 \pm 0.118$ & 4.26 \\
\hline $\mathrm{B}$ & $702 ; 667$ & 708 & 702 & $5.75 \pm 0.0302$ & $0.433 \pm 0.128$ & 4.31 \\
\hline $\mathrm{C}$ & $702 ; 667$ & 709 & 702 & $5.83 \pm 0.0290$ & $0.408 \pm 0.118$ & 4.07 \\
\hline $\mathrm{D}$ & $705 ; 673$ & 711 & 704 & $5.55 \pm 0.0274$ & $0.495 \pm 0.161$ & 4.93 \\
\hline
\end{tabular}

were $\eta$ the solvent viscosity, $\mathrm{V}$ the molecular volume, $k$ is the Boltzman constant and $T$ the absolute temperature. The calculated molecular volume values are shown in Table 2 . The experimental molecular volumes for the isomers were $4.26 \times 10^{-27} \mathrm{~m}^{3}$, $4.31 \times 10^{-27} \mathrm{~m}^{3}, 4.07 \times 10^{-27} \mathrm{~m}^{3}$ and $4.93 \times 10^{-27} \mathrm{~m}^{3}$, respectively. These experimental volumes were within range of the theoretically calculated molecular volume of $1.29 \times 10^{-27} \mathrm{~m}^{3}$ for an unsubstituted Pc compound..$^{13}$ In comparison with the $\alpha$ derivative, these values are significantly larger and this suggests greater solvent interaction for the $\beta$ derivative.

\subsection{Characterization of the Positional Isomers using}

Non-linear Optical (NLO) Parameters and DFT Calculations

The Z-scan technique was the experimental method used to measure nonlinear absorption. The open aperture Z-scan experiment was carried out in DCM. The curves were similar for all the isomers, displaying strong non-linear absorption behaviour with reverse saturable absorption (RSA) profiles (Fig. 7). The second-order hyperpolarizability, $\left(\beta_{\text {eff }}\right)$ values were calculated using Equation (11) and can be seen in Table 3. The $\beta_{\text {eff }}$ value characterizes the strength of nonlinearity of the non-linear plots. Non-linear fits of $q_{0}\left(z_{\mathrm{s}}\right)$ (Fig. 7) were constructed to obtain the experimental $\beta_{\text {exp }}$ values of the respective isomers. The $\beta_{\exp }$ values are compared with those reported previously for the $\alpha$ derivatives $^{41,42}$ and display the following trend: Fraction A $(9.31 \times$ $\left.10^{-10} \mathrm{mMW}^{-1}\right)>$ Fraction $\mathrm{B}\left(7.89 \times 10^{-10} \mathrm{mMW}^{-1}\right)>$ Fraction C $\left(7.32 \times 10^{-10} \mathrm{mMW}^{-1}\right)>$ Fraction D $\left(1.77 \times 10^{-10} \mathrm{mMW}^{-1}\right)$. Substitution at the $\alpha$ positions causes complex charge distribution which significantly affects the molecular orbitals of the Pc ring. It is expected that substitution at the $\beta$ position will have no effect on the Pc's molecular orbitals. As a result the influence of substitution position can be used to relate its effect on NLO properties. The $\beta_{\exp }$ observed for the $\beta$ derivative are smaller than those observed for the $\alpha$ derivative, this correlates well with the fluorescence lifetimes. Since long fluorescence lifetimes suggests low triplet state population, a low populated triplet state results in a low $\beta_{\exp }$ value. $^{43}$.

The symmetry of the four fractions was confirmed by means of DFT analysis of the calculated $\beta_{\text {eff }}$ values, as $\beta_{\text {eff }}$ values are sensitive to symmetry. ${ }^{44}$ Table 3 shows the measured and DFT
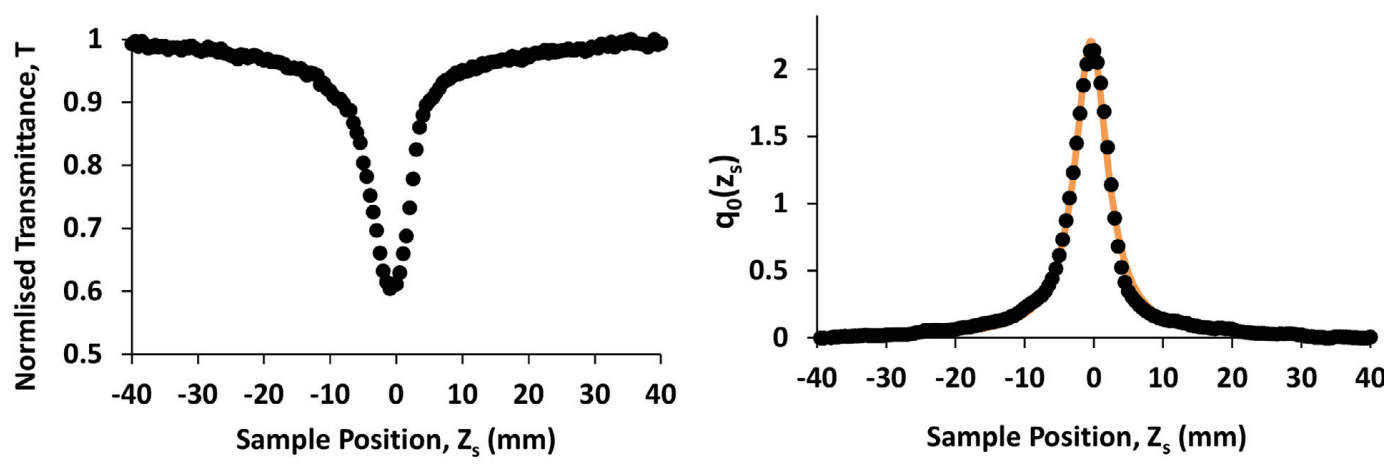

Figure 7 Z-scan (left) and nonlinear fit (right) curves $\left(q_{0}\left(\mathrm{z}_{\mathrm{s}}\right)\right)$ for Fraction A. All experiments were conducted in DCM solution. 
Table 3 Experimental Z-scan results for nonlinear absorption coefficient $\left(\beta_{\exp }\right)$ and second order hyperpolarizability $\left(\beta_{\text {eff }}\right)$, maximum value at the beam waist $\left(\mathrm{Q}_{0}\right)$ and Rayleigh length $\left(\mathrm{Z}_{\mathrm{R}}\right)$.

\begin{tabular}{ccccccc}
\hline Fraction & Symmetry & $\begin{array}{c}\beta_{\text {exp }} \\
/ \times 10^{-10} \mathrm{~m} \mathrm{MW}^{-1}\end{array}$ & $\begin{array}{c}\beta_{\text {eff }} \\
/ \times 10^{-28} \mathrm{esu}\end{array}$ & $\mathrm{Q}_{0}$ & $\begin{array}{c}\mathrm{Z}_{\mathrm{R}} \\
/ \mathrm{mm}\end{array}$ \\
\hline $\mathrm{A}$ & $\mathrm{C}_{4 \mathrm{~h}}$ & 9.31 & 3.60 & 2.21 & 2.85 \\
$\mathrm{~B}$ & $\mathrm{D}_{2 \mathrm{~h}}$ & 7.89 & 3.59 & 1.97 & 2.71 \\
$\mathrm{C}$ & $\mathrm{C}_{\mathrm{s}}$ & 7.32 & 3.55 & 1.68 & 2.48 \\
$\mathrm{D}$ & $\mathrm{C}_{2 \mathrm{v}}$ & 1.77 & 2.85 & 1.03 & 2.25 \\
\hline
\end{tabular}

calculated $\beta_{\text {eff }}$ values used to certify the symmetry of each isomer.

The symmetry assignment was found to follow a similar trend to symmetry assignment for $4 \alpha$-(4-tert-butylphenoxy)phthalocyanines, ${ }^{13}$ apart from the $\mathrm{C}_{2 \mathrm{v}}$ and $\mathrm{C}_{\mathrm{s}}$ symmetries. The $\mathrm{C}_{2 \mathrm{v}} \beta_{\exp }$ value for $4 \alpha$-(4-tert-butylphenoxy)phthalocyanines was found to be higher with respect to $\mathrm{C}_{\mathrm{s}}$ symmetry. However, similar to the $4 \alpha$-(4-tert-butylphenoxy)phthalocyanines the $\mathrm{C}_{2 \mathrm{v}}$ and $\mathrm{C}_{\mathrm{s}} \beta_{\exp }$ values were found to be the lowest compared to other symmetries. Similar to $4 \alpha$-(4-tert-butylphenoxy)phthalocyanines, the theoretical $\beta_{\text {eff }}$ values indicate that the $\mathrm{C}_{4 \mathrm{~h}}$ has the highest NLO response. The $\beta_{\text {eff }}$ values for $\mathrm{C}_{4 \mathrm{~h}}$ and $\mathrm{D}_{2 \mathrm{~h}}$ isomers of $4 \beta$-(4-tertbutylphenoxy)phthalocyanines where found to have a very small difference, making it ambiguous to assign based on theoretical calculations only. Hence the assignment was also based on the assignment observed for $4 \alpha$-(4-tert-butylphenoxy)phthalocyanines. ${ }^{13}$

The optimized geometries of the isomers were simulated by DFT calculations (Fig. 8). The theoretical molecular anisotropy ratio $(\rho)$, depolarization ratio (DR), dipolar $\left(\phi_{J=1}\right)$ and octupolar $\left(\phi_{I=3}\right)$ contributions values were calculated using Equations (2-9) respectively and can be viewed in Table 4 .

The dipolar $\left(\phi_{J=1}\right)$ and octupolar $\left(\phi_{J=3}\right)$ contribution trend of the

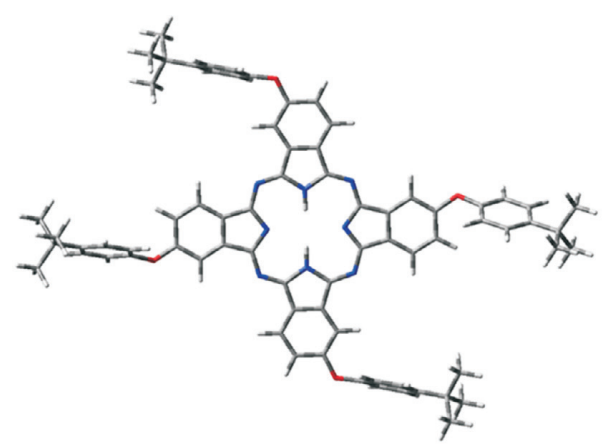

$\mathrm{C}_{4 \mathrm{~h}}$

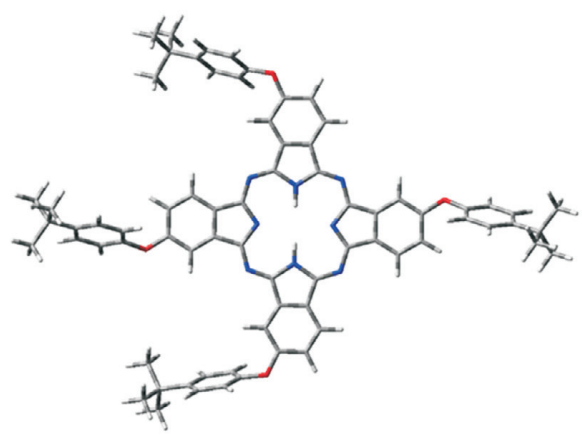

$\mathrm{C}_{\mathrm{s}}$ four positional isomers (Table 4) suggest the following trend of decreasing dipolar contribution $\mathrm{C}_{4 \mathrm{~h}}>\mathrm{D}_{2 \mathrm{~h}}>\mathrm{C}_{\mathrm{s}}>\mathrm{C}_{2 \mathrm{v}}$. This study has not been done for the $\alpha$ derivative hence no comparison can be made.

The molecular anisotropy ratio $(\rho)$ was employed to evaluate the ratio of dipolar and octupolar contributions to the hyperpolarizability tensor. The $\rho$ ratio ranges between 0 (pure dipolar) and $\infty$ (pure octupolar) ${ }^{23}$ The $\rho$ for the four isomers suggest that $\mathrm{C}_{2 \mathrm{v}}$ has the most octupolar contribution. The theoretical $\beta_{\text {eff }}$ values follow a similar trend to dipolar contribution, the greater the dipolar contribution the greater the $\beta_{\text {eff }}$ values.

To compare the relative magnitude of the dipolar and octupolar components of the second-order NLO response, $\phi_{\mathrm{J}=1}$ and $\phi_{\mathrm{I}=3}$ values were plotted with respect to $\rho$. Figure 9 provides a quantitative classification of the NLO system with regard to dipolar or octupolar character of the isomers. The $\mathrm{C}_{4 \mathrm{~h}}$ and $\mathrm{D}_{2 \mathrm{~h}}$ isomers fall to the left of the $\rho=1$ axis indicating a pronounced dipolar character. The $\mathrm{C}_{\mathrm{s}}$ and $\mathrm{C}_{2 \mathrm{v}}$ isomers fall to the right of the $\rho=1$ axis indicating a pronounced octupolar character.

The depolarization ratio (DR) was assessed to provide supporting information on the molecular geometries of the isomers. The minimal depolarization for dipoles is $(\rho=0) D_{\min }=4 / 27=$

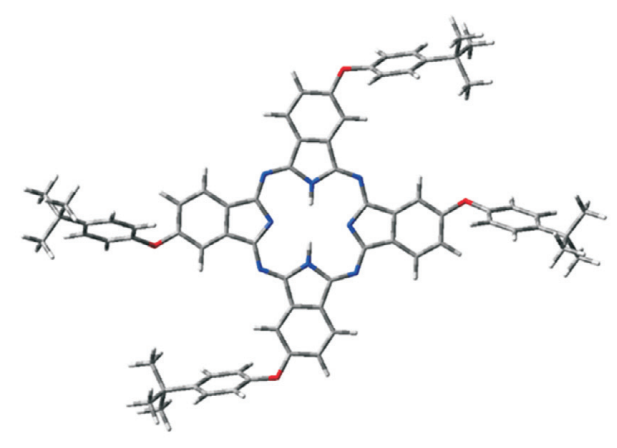

$\mathrm{D}_{2 \mathrm{~h}}$

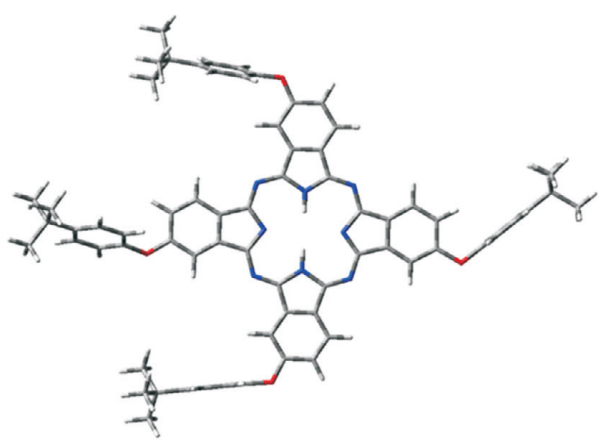

$\mathrm{C}_{2 \mathrm{v}}$

Figure 8 Optimized structures of $4 \beta$-(4-tert-butylphenoxy)phthalocyanines constitutional isomers with $\mathrm{C}_{4 h}, \mathrm{D}_{2 \mathrm{~h}}, \mathrm{C}_{\mathrm{s}}$ and $\mathrm{C}_{2 \mathrm{v}}$ symmetry substitution patterns. The structures were optimized at the B3LYP level of theory with the 6-31G(d) basis set. 
Table 4 DFT calculated values of $\rho, \phi_{J=1}, \phi_{J=3}$ and DR using the B3LYP functional and 6-31G(d) basis set.

\begin{tabular}{cccccc}
\hline Fraction & Symmetry & $\rho$ & $\phi_{J=1}$ & $\phi_{J=3}$ & DR \\
\hline $\mathrm{A}$ & $\mathrm{C}_{4 \mathrm{~h}}$ & 0.362 & 0.734 & 0.266 & 0.045 \\
$\mathrm{~B}$ & $\mathrm{D}_{2 \mathrm{~h}}$ & 0.367 & 0.730 & 0.270 & 0.047 \\
$\mathrm{C}$ & $\mathrm{C}_{\mathrm{s}}$ & 3.803 & 0.208 & 0.792 & 0.400 \\
$\mathrm{D}$ & $\mathrm{C}_{2 \mathrm{v}}$ & 8.138 & 0.109 & 0.890 & 0.499 \\
\hline
\end{tabular}

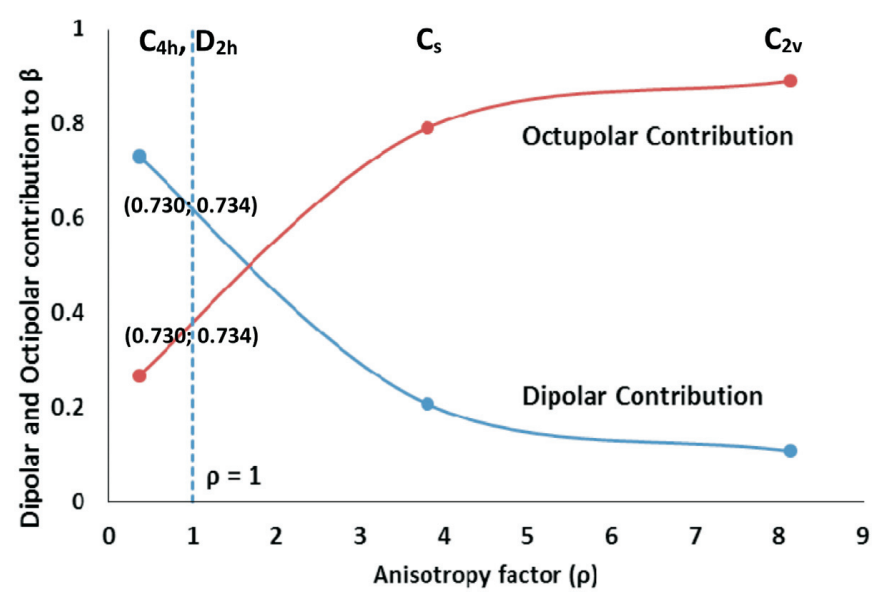

Figure 9 Dipolar and octupolar contributions to the second-order NLO response as function of anisotropy factor $\rho$.

$0.148^{45}$ and the maximum depolarization for pure octupoles is $(\rho=\infty) \mathrm{D}_{\max }=2 / 3=0.667 .^{45,46}$ The $\mathrm{C}_{\mathrm{s}}$ and $\mathrm{C}_{2 \mathrm{v}}$ isomers had DR values of 0.400 and 0.499 reflecting their octupolar character. The $\mathrm{C}_{4 \mathrm{~h}}$ and $\mathrm{D}_{2 \mathrm{~h}}$ isomers had DR values of 0.047 and 0.045 reflecting their strong dipolar character towards NLO activity.

Figure 10 displays the polar plot of the harmonic light intensity as a function of the incoming fundamental beam polarization angle. The graphs provide a graphical interpretation of the dipolar and octupolar parameters of the isomers. The results coincide with Fig. 9, indicating that the $\mathrm{C}_{4 \mathrm{~h}}$ and $\mathrm{D}_{2 \mathrm{~h}}$ isomers can be considered dipolar molecules with dipolar contributions of $73 \%$ each. The $\mathrm{C}_{\mathrm{s}}$ and $\mathrm{C}_{2 \mathrm{v}}$ isomers display strong octupolar character with $79 \%$ and $89 \%$ octupolar contributions respectively. Octupolar molecules have been used as NLO chromophores as they lack a permanent dipole moment. They can form noncentrosymmetric bulk materials to obtain a large macroscopic second-order NLO response. ${ }^{23,46,47}$ Due to their larger octupolar contributions the $\mathrm{C}_{\mathrm{s}}(79 \%)$ and $\mathrm{C}_{2 \mathrm{v}}(89 \%) \mathrm{H}_{2}$ Pc isomers are more suitable in films (or bulk material) for NLO applications, which makes use of second-order hyperpolarizability than the $\mathrm{C}_{4 \mathrm{~h}}(73 \%)$ and $\mathrm{D}_{2 \mathrm{~h}}(73 \%) \mathrm{tBuH}_{2} \mathrm{Pc}$ isomers.

\section{Conclusion}

According to the characterization techniques used, it can be concluded that the proposed isomers of metal-free $4 \beta$-(4-tertbutylphenoxy)phthalocyanine were successfully synthesized and separated. The experimental volume values of the isomers were determined to be within range of the theoretically calculated molecular volume of $1.29 \times 10^{-27} \mathrm{~m}^{3}$ for an unsubstituted Pc compound. The fluorescence lifetimes of the isomers were measured and found to be in the 5.5-5.8 ns range, which is typical for monomeric Pc compounds. The non-linear optical behaviour of the isomers showed reverse saturable absorption with the higher symmetry $\mathrm{C}_{4 \mathrm{~h}}$ isomer displaying enhanced NLO properties. A similar $\beta_{\exp }$ value trend was observed for the $4 \alpha$-(4-tertbutylphenoxy)phthalocyanine..$^{13}$ The isomers with high dipolar contribution $\left(\mathrm{C}_{4 \mathrm{~h}}(73 \%)\right.$ and $\left.\mathrm{D}_{2 \mathrm{~h}}(73 \%)\right)$ showed better NLO

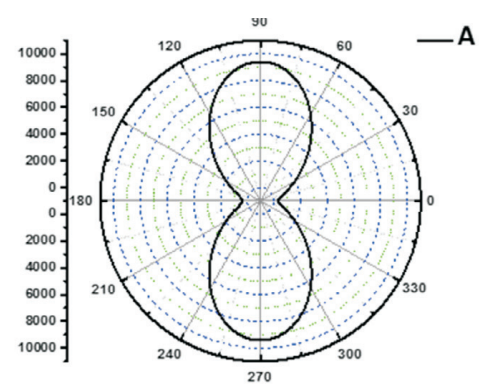

Dipolar

Molecule
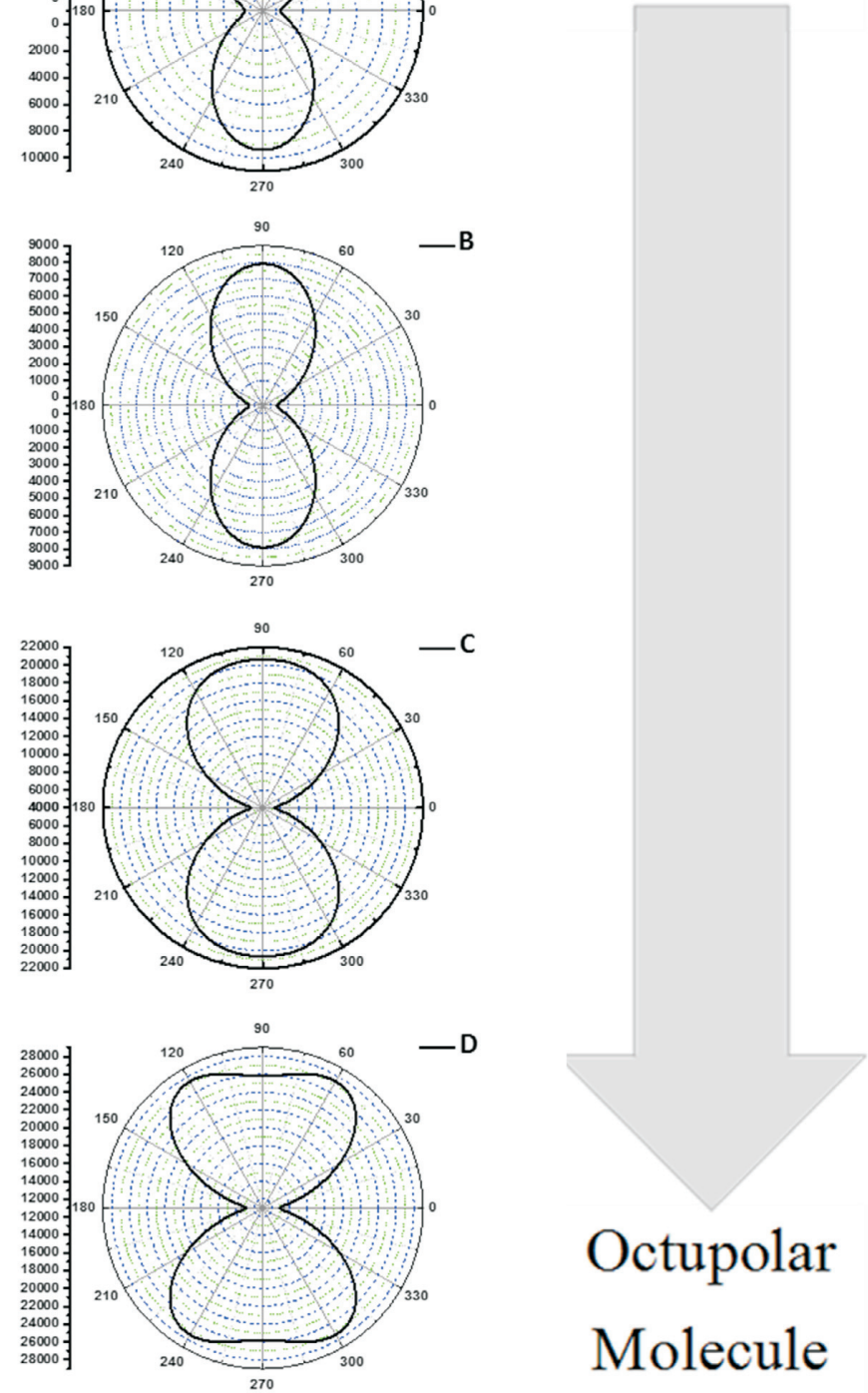

Molecule

Figure 10 Light intensity as a function of the polarization angle by polar representation of $\mathrm{C}_{4 \mathrm{~h}}(\mathrm{~A}), \mathrm{D}_{2 \mathrm{~h}}(\mathbf{B}), \mathrm{C}_{\mathrm{s}}(\mathbf{C})$, and $\mathrm{C}_{2 \mathrm{v}}(\mathbf{D})$ isomers.

absorption coefficient with respect to other isomers in solution. However, theoretically calculated octupolar ratio suggest that $\mathrm{C}_{\mathrm{s}}$ $(79 \%)$ and $\mathrm{C}_{2 \mathrm{v}}(89 \%) \mathrm{H}_{2} \mathrm{Pc}$ isomers are better suited for application as films compared to $\mathrm{C}_{4 \mathrm{~h}}(73 \%)$ and $\mathrm{D}_{2 \mathrm{~h}}(73 \%) \mathrm{H}_{2} \mathrm{Pc}$ isomers. This applies for applications which make use of second-order hyperpolarizability $\left(\beta_{\text {eff }}\right)$.

\section{Acknowledgements}

This work was supported by the Department of Science, Republic of South Africa, and the National Research Foundation through the Thuthuka funding instrument (Grant number 
94046). The authors are thankful to the University of KwaZuluNatal and Nanotechnology Innovation Center (NIC) based at Rhodes University.

\section{References}

1 W. Shi, B. Peng, Y. Guo, L. Lin, T. Peng and R. Li, Synthesis of asymmetric zinc phthalocyanine with bulky diphenylthiophenol substituents and its photovoltaic performance for dye-sensitized solar cells, J. Photochem. Photobiol., A, 2016, 321, 248-256.

2 N. Nombona, K. Maduray, E. Antunes, A. Karsten and T. Nyokong, Synthesis of phthalocyanine conjugates with gold nanoparticles and liposomes for photodynamic therapy, J. Photochem. Photobiol., B, 2012, 107, 35-44.

3 E.T. Saka, G. Sarkia, H. Kantekin and A. Koca, Electrochemical, spectroelectrochemical and catalytical properties of new $\mathrm{Cu}(\mathrm{II})$ and Co(II) phthalocyanines, Synth. Met., 2016, 214, 82-91.

4 Z. Wang, M. Lee, E.S. Choi, J. Poston and M.S. Seehra, Low temperature, high magnetic field investigations of the nature of magnetism in the molecular semiconductor $\beta$-cobalt phthalocyanine $\left(\mathrm{C}_{32} \mathrm{H}_{16} \mathrm{CoN}_{8}\right)$, J. Magn. Magn. Mater., 2016, 407, 83-86.

5 G. de la Torre, P. Vázquez, F. Agulló-López and T. Torres, Role of structural factors in the nonlinear optical properties of phthalocyanines and related compounds, Chem. Rev., 2004, 104, 3723-3750.

6 A. Bilgin, B. Ertem and Y. Gök, Highly organosoluble metal-free phthalocyanines and metallophthalocyanines: synthesis and characterization, Eur. J. Inorg., 2007, 12, 1703-1712.

7 N. Venkatram, D. Narayana Rao, L. Giribabu and S. Venugopal Rao, Femtosecond nonlinear optical properties of alkoxy phthalocyanines at $800 \mathrm{~nm}$ studied using Z-Scan technique, Chem. Phys. Lett., 2008, 464, 211-215.

8 R.S.S. Kumar, S. Venugopal Rao, L. Giribabu and D. Narayana Rao, Femtosecond and nanosecond nonlinear optical properties of alkyl phthalocyanines studied using Z-scan technique, Chem. Phys. Lett. 2007, 447, 274-278.

9 J.P. Fitzgerald, P.D. Huffman, I.A. Brenner, J.J. Wathen, G. Beadie, R.G.S. Pong, J.S. Shirk and S.R. Flom, Synthesis, chemical characterization and nonlinear optical properties of thallium(III) phthalocyanine halide complexes, Opt. Mater. Express, 2015, 5, 1560-1578.

10 Y. Zhang, Z. Zhao, C. Yao, L. Yang, J. Li and P. Yuan, The nonlinear absorption and optical limiting in phenoxy-phthalocyanines liquid in nano- and femto-second regime: experimental studies, Opt. Laser Technol., 2014, 58, 207-214

11 O.M. Bankole and T. Nyokong, Nonlinear optical response of a low symmetry phthalocyanine in the presence of gold nanoparticles when in solution or embedded in poly acrylic acid polymer thin films, J. Photochem. Photobiol., A, 2016, 320, 8-17.

12 J. Mack and N. Kobayashi, Low symmetry phthalocyanines and their analogues, Chem. Rev, 2011, 111, 281-321.

13 G. Ngubeni, J. Britton, J. Mack, E. New, I, Hancox, M. Walker, T. Nyokong, S.T. Jones and S. Khene, Spectroscopic and nonlinear optical properties of the four positional isomers of $4 \alpha$-(4-tert-butylphenoxy)phthalocyanines, J. Mater. Chem. C, 2015, 3, 10705-10714.

14 J.G. Young and W. Onyebuagu, Synthesis and characterization of di-disubstituted phthalocyanines, J. Org. Chem., 1990, 55, 2155-2159.

15 P. Tau and T. Nyokong, Synthesis and electrochemical characterisation of a- and b-tetra-substituted oxo(phthalocyaninato) titanium(IV) complexes, Polyhedron, 2006, 25, 1802-1810.

16 A.D. Becke, Density-functional thermochemistry. III. The role of exact exchange J. Chem. Phys. 1993, 98, 5648-5652.

17 C. Lee, W. Yang and R.G. Parr, Development of the Colle-Salvetti correlation-energy formula into a functional of the electron density, Phys. Rev. B, 1988, 37, 785-789.

18 S.H. Vosko, L. Wilk and M. Nusair, Accurate spin-dependent electron liquid correlation energies for local spin density calculations: a critical analysis, Can. J. Phys., 1980, 58, 1200-1211.

19 P.J. Stephens, F.J. Devlin, C.F. Chabalowski and M.J. Frisch, Ab initio calculation of vibrational absorption and circular dichroism spectra using density functional force fields, J. Phys. Chem. 1994, 98, 11623-11627.

20 M.J. Frisch, G.W. Trucks, H.B. Schlegel, G.E. Scuseria, M.A. Robb, J.R Cheeseman, J.A. Montgomery Jr., T. Vreven, K.N. Kudin, J.C. Burant, J.M. Millam, S.S. Iyengar, J. Tomasi, V. Barone, B. Mennucci, M. Cossi,
G. Scalmani, N. Rega, G.A. Petersson, H. Nakatsuji, M. Hada, M. Ehara, K. Toyota, R. Fukuda, J. Hasegawa, M. Ishida, T. Nakajima, Y. Honda, O. Kitao, H. Nakai, M. Klene, X. Li, J.E. Knox, H.P. Hratchian, J.B. Cross, V. Bakken, C. Adamo, J. Jaramillo, R. Gomperts, R.E. Stratmann, O. Yazyev, A.J. Austin, R. Cammi, C. Pomelli, J.W. Ochterski, P.Y. Ayala, K. Morokuma, G.A. Voth, P. Salvador, J.J. Dannenberg, V.G. Zakrzewski, S. Dapprich, A.D. Daniels, M.C. Strain, O. Farkas, D.K. Malick, A.D. Rabuck, K. Raghavachari, J.B. Foresman, J.V.D.J. Fox, T. Keith, M.A. Al-Laham, C.Y. Peng, A. Nanayakkara, M. Challacombe, P.M.W. Gill, B. Johnson, W. Chen, M.W. Wong, C. Gonzalez and J.A. Pople, Gaussian 03, Revision E.01, Gaussian, Inc., Wallingford, CT, 2004.

21 P.S. Liyanage, R.M. de Silva and K.M. Nalin de Silva, Nonlinear optical (NLO) properties of novel organometallic complexes: high accuracy density functional theory (DFT) calculations, J. Mol. Struct.: THEOCHEM, 2003, 639, 195-201.

22 M.J. Frisch, G.W. Trucks, H.B. Schlegel, G.E. Scuseria, M.A. Robb, J.R. Cheeseman, G. Scalmani, V. Barone, B. Mennucci, G.A. Petersson, H. Nakatsuji, M. Caricato, X. Li, H.P. Hratchian, A.F. Izmaylov, J. Bloino, G. Zheng, J.L. Sonnenberg, M. Hada, M. Ehara, K. Toyota, R. Fukuda, J. Hasegawa, M. Ishida, T. Nakajima, Y. Honda, O. Kitao, H. Nakai, T. Vreven, J.A. Montgomery, Jr., J.E. Peralta, F. Ogliaro, M. Bearpark, J.J. Heyd, E. Brothers, K.N. Kudin, V. N. Staroverov, R. Kobayashi, J. Normand, K. Raghavachari, A. Rendell, J.C. Burant, S.S. Iyengar, J. Tomasi, M. Cossi, N. Rega, J.M. Millam, M. Klene, J.E. Knox, J.B. Cross, V. Bakken, C. Adamo, J. Jaramillo, R. Gomperts, R.E. Stratmann, O. Yazyev, A.J. Austin, R. Cammi, C. Pomelli, J.W. Ochterski, R.L. Martin, K. Morokuma, V.G. Zakrzewski, G.A. Voth, P. Salvador, J.J. Dannenberg, S. Dapprich, A.D. Daniels, Ö. Farkas, J.B. Foresman, J. V. Ortiz, J. Cioslowski and D.J. Fox, Gaussian 09, Revision D.01, Gaussian, Inc., Wallingford CT, 2009.

23 L. Zhang, D. Qi, L. Zhao, C. Chen, Y. Bian and W. Li, Density functional theory study on subtriazaporphyrin derivatives: dipolar/ octupolar contribution to the second-order nonlinear optical activity, J. Phys. Chem, 2012, 116, 10249-10256.

24 A. Plaquet, M. Guillaume, B. Champagne, F. Castet, L. Ducasse, J. Pozzo and V. Rodriguez, In silico optimization of merocyaninespiropyran compounds as second-order nonlinear optical molecular switches, Phys. Chem. Chem. Phys, 2008, 10, 6223-6232.

25 F. Castet, E. Bogdan, A. Plaquet, L. Ducasse, B. Champagne and V. Rodriguez, Reference molecules for nonlinear optics: a joint experimental and theoretical investigation, J. Chem. Phys., 2012, 136, 024506-0245015.

26 P. Chandra Ray, Size and shape dependent second order nonlinear optical properties of nanomaterials and its application in biological and chemical sensing, Chem Rev., 2010, 110, 5332-5365.

27 A.Y Tolbin, V.E. Pushkarev, G.F. Nikitin and L.G. Tomilova, Heteroligand and heteronuclear clamshell-type phthalocyanines: selective preparation, spectral properties, and synthetic application, Tetrahedron Lett., 2009, 50, 4848-4850.

28 K. Palewska, J. Sworakowski and J. Lipiński, Molecular aggregation in soluble phthalocyanines - Chemical interactions vs. $\pi$-stacking, Opt. Mater., 2012, 34, 1717-1724.

29 S. Sergeyev, E. Pouzet, O. Debever, J. Levin, J. Gierschner, J. Cornil, R.G. Aspe and Y.H. Geerts, Liquid crystalline octaalkoxycarbonyl phthalocyanines: design, synthesis, electronic structure, selfaggregation and mesomorphism, J. Mater. Chem., 2007, 17, 1777-1784.

30 M. Gouterman, The Porphyrins, Vol. III, Part A, (D. Dolphin, ed.), Academic Press, New York, USA, 1978.

31 M. Ozer, A. Altındal, A.R. Ozkaya, M. Bulut and O. Bekaroğlu, Synthesis, characterization and some properties of novel bis(pentafluorophenyl)methoxyl substituted metal free and metallophthalocyanines, Polyhedron, 2006, 25, 3593-3602.

32 H. Isago, Optical Spectra of Phthalocyanines and Related Compounds - A Guide for Beginners, Springer, Tsukuba, Japan, 2015.

33 Z. Gasyna, N. Kobayashi and M.J. Stillman, Optical absorption and magnetic circular dichroism studies of hydrogen, copper(II), zinc(II), nickel(II), and cobalt(II) crown ether-substituted monomeric and dimeric phthalocyanines, J. Chem. Soc., Dalton Trans., 1989, 12, 2397-2405.

34 J. Mack, N. Kobayashi and M.J. Stillman, Re-examination of the emission properties of alkoxy-and thioalkyl-substituted phthalocyanines, J. Inorg. Biochem., 2010, 104, 310-317. 
35 M. Dulski, M. Kempa, P. Kozub, J. Wójcik, M. Rojkiewicz, P. Kuś, A Szurko, A. Ratuszna and R. Wrzalik, DFT/TD-DFT study of solvent effect as well the substituents influence on the different features of TPP derivatives for PDT application, Spectrochim. Acta, Part A, 2013, $104,315-327$.

36 Y. Yılmaz,J. Mack, M.K. Sener, M. Sönmez and T. Nyokong, Synthesis, photophysicochemical properties and TD-DFT calculations of tetrakis(2-benzoyl-4-chlorophenoxy) phthalocyanines, J. Porphyrins Phthalocyanines, 2014, 18, 326-335.

37 J.W. Owens and M. Robins, Phthalocyanine photophysics and photosensitizer efficiency on human embryonic lung fibroblasts, J. Porphyrins Phthalocyanines, 2001, 5, 460-464.

38 P. Tau and T. Nyokong, Electrochemical characterisation of tetra- and octa-substituted oxo(phthalocyaninato)titanium(IV) complexes, Electrochim. Acta, 2007, 52, 3641-3650.

39 Z. Petrášiek and D. Phillips, A time-resolved study of concentration quenching of disulfonated aluminium phthalocyanine fluorescence, Photochem. Photobiol. Sci., 2003, 2, 236-244.

40 J.W Borst, M.A. Hink, A. van Hoek and A.J.W.G. Visser, Effects of refractive index and viscosity on fluorescence and anisotropy decays of enhanced cyan and yellow fluorescent protein, J. Fluoresc., 2005, 15, 153-160.
41 E.M. García-Frutos, S.M. O'Flaherty, E.M. Maya, G. de la Torre, W. Blau, P. Vázqueza and T. Torres, Alkynyl substituted phthalocyanine derivatives as targets for optical limiting, J. Mater. Chem., 2003, 13, 749-753.

42 C. Nitschke, S.M. O'Flaherty, M. Kroll, J.J. Doyle and W.J. Blau, Optical properties of zinc phthalocyanine nanoparticle dispersions, Chem. Phys. Lett., 2003, 383, 555-560.

43 M.Y. Berezin and S. Achilefu, Fluorescence lifetime measurements and biological imaging, Chem. Rev., 2010, 110, 2641-2684.

44 T. Verbiest, S.V. Elshocht, A. Persoons, C. Nuckolls, K.E. Phillips and T.J. Katz, Second-order nonlinear optical properties of highly symmetric chiral thin films, Langmuir, 2001, 17, 4685-4687.

45 N.B. McKeown, Phthalocyanine Materials: Synthesis, Structure and Function, Cambridge University Press, Cambridge, 1998.

46 M.M. Ayhan, A. Singh, E. Jeanneau, V. Ahsen, J. Zyss, I. Ledoux-Rak, A. Gül Gürek, C. Hirel, Y. Bretonnière and C. Andraud, ABAB homoleptic bis(phthalocyaninato) lanthanide(iii) complexes: original octupolar design leading to giant quadratic hyperpolarizability, Inorg. Chem., 2014, 53, 4359-4370.

47 Y. Lee, S. Jeon and M. Cho, Molecular polarizability and first hyperpolarizability of octupolar molecules: donor-substituted triphenylmethane dyes, J. Am. Chem. Soc., 1998, 120, 10921-10927. 


\section{Supplementary material to:}

D. Gounden, G.N. Ngubeni, M.S. Louzada, S. Khene, J. Britton and N. Nombona,

Synthesis, Spectroscopic and DFT Characterization of $4 \beta$-(4-tert-Butylphenoxy)phthalocyanine Positional Isomers for Non-linear Optical Absorption,

S. Afr. J. Chem., 2017, 70, 49-59. 


\title{
Supplementary Information, S. Afr. J. Chem
}

\section{Synthesis, spectroscopic and DFT characterisation of

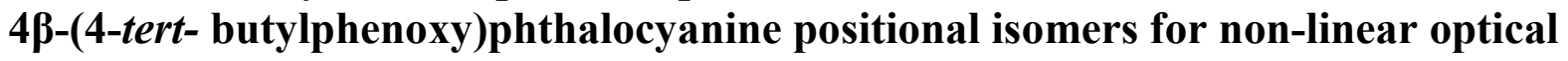 absorption}

\author{
Denisha Gounden ${ }^{\mathrm{a}, \mathrm{b}}$, Grace N. Ngubeni ${ }^{\mathrm{b}}$, Marcel S. Louzada ${ }^{\mathrm{b}}$, Samson Khene ${ }^{\mathrm{b}}$, Jonathan \\ Britton $^{\mathrm{b}}$, Nolwazi Nombona ${ }^{\mathrm{a}^{*}}$ \\ ${ }^{a}$ School of Chemistry and Physics, University of KwaZulu-Natal, Durban, 4000, South Africa \\ ${ }^{b}$ Department of Chemistry, Rhodes University, Grahamstown, 6140, South Africa
}

\section{TABLE OF CONTENTS}

1. Equations used for Z-Scan measurements.

2. Input file for the four positional isomers and optimised Cartesian coordinates of the structures.

3. Figure S1. MALDI-TOF spectra of $\mathrm{tBuH}_{2} \mathrm{Pc}$ positional isomers.

4. Figure S2. Z-scan (left) and NLO fit (right) for isomers $D_{2 h}, C_{s}$ and $C_{2 v}$.

5. Figure S3. TCSPC traces of the four positional isomers. 


\section{Equations used for Z-Scan measurements}

The normalized open aperture Z-scan transmittance was measured in order to experimentally determine the second order NLO parameter. This normalized transmittance can be calculated by Equation (S1) ${ }^{1,2:}$

$T_{n}\left(z_{S}\right)=\frac{1}{A q_{0}\left(z_{S}\right)} \int_{-\infty}^{+\infty} \ln \left[1+q_{0}\left(z_{S}\right) f(\tau)\right] d \tau$

Where $f(\tau)$ is a function of time detailing the temporal profile of the Gaussian pulses in the form of $f(\tau)=e^{\left(\tau^{2}\right)} . A$ is the normalization constant equal to $\int_{-\infty}^{+\infty} f(\tau) \mathrm{d} \tau$, whilst the $q_{0}\left(z_{\mathrm{s}}\right)$ parameter characterizes the strength of the nonlinearity. In the event of a circular Gaussian beam, it is represented by Equation (S2) ${ }^{3}$ :

$$
q_{0}\left(z_{S}\right)=\frac{2 \beta P_{0} L_{\mathrm{eff}}}{\pi w^{2}\left(z_{S}\right)}
$$

Where $\beta$ is the nonlinear absorption coefficient of the material, $P_{0}$ is the peak power of the pulses and $L_{\text {eff }}$ is the effective propagation length in the material, given by the following Equation (S3):

$L_{e f f}=\frac{1-\mathrm{e}^{-(\alpha L)}}{\alpha}$

Where $L$ is the sample length and $\alpha$ is the linear absorption coefficient which is calculated by Equation (S4):

$\alpha=\frac{h v}{N} \beta$

Where $\mathrm{h}$ is Planck's constant, $v$ is the frequency of the laser excitation and $\mathrm{N}$ corresponds to the number of active species per unit volume. The $w\left(\mathrm{z}_{\mathrm{s}}\right)$ parameter (Equation $(\mathrm{S} 2)$ ) is the beam width at the sample plane defined as the distance from the beam centre to the point where the intensity reduces to $1 / e^{2}$ of its axis value. The $w\left(\mathrm{z}_{\mathrm{s}}\right)$ parameter is defined by Equation (S5) ${ }^{1}$ : 
$w\left(z_{S}\right)=w_{0} \sqrt{\left(\frac{z_{s}-z_{0}}{z_{R}}\right)^{2}}$

Where $\boldsymbol{w}_{0}$ is the beam width at the focal point and $z_{0}$ is the location of the beam focus. The $z_{\mathrm{R}}$ parameter is the Rayleigh length and is given by the relation in Equation (S6):

$\mathrm{Z}_{\mathrm{R}}=\frac{\pi w_{0}^{2}}{\lambda}$

Where $\lambda$ is the wavelength. Equations (S1-S6) are adequate for determining the nonlinear absorption coefficient $(\beta)$ from the experimentally measured transmittance. G. Tsigaridas et. al derived an analytical formula Equation (S7) that provides values for $q_{0}\left(\mathrm{z}_{\mathrm{s}}\right)$ directly from the normalized transmittance $\mathrm{T}_{\mathrm{n}}\left(\mathrm{Z}_{\mathrm{s}}\right)^{1}$.

$q_{0}=\left\{\begin{array}{l}a_{0}+a_{1} T_{n}\left(z_{s}\right)+a_{2} T_{n}^{2}\left(z_{s}\right)+a_{3} T_{n}^{3}\left(z_{s}\right) \text { for } T_{n}\left(z_{s}\right) \leq 0.75 \\ c_{0}+c_{1}\left[T_{n}\left(z_{s}\right)\right]^{2} \text { for } T_{n}\left(z_{s}\right) \geq 0.75\end{array}\right.$

Where the coefficients $a_{0}, a_{1}, a_{2}, a_{3}, c_{0}, c_{1}, c_{2}$ for Gaussian pulses are reported as 15.66, -37.45, $30.76,-8.97,-2.301,2.156,-1.563$ respectively ${ }^{1}$. Their work demonstrates that this technique allows for the simple determination of $\beta$, and is robust in the presence of signal noise ${ }^{1}$. Absorption coefficient $(\beta)$ value and the beam parameters $z_{0}$ and $z_{\mathrm{S}}$ can be determine from the $q_{0}\left(z_{\mathrm{s}}\right)$ values obtained from Equation (S7). Substituting Equation (S5) into Equation (S2), $q_{0}\left(z_{\mathrm{s}}\right)$ is then defined by Equation (S8):

$q_{0}\left(z_{S}\right)=\frac{Q_{0}}{1+\left(z_{S}+z_{0}\right)^{2} / z_{R}^{2}}$

Where:

$Q_{0}=\frac{2 \beta P_{0} L_{\mathrm{eff}}}{\pi w_{0}^{2}}=\frac{2 \beta P_{0} L_{\mathrm{eff}}}{\lambda\left(z_{R}\right)}$

Equation (S7) describes a Gaussian plot with $Q_{0}$ as the maximum value at the beam waist $\left(z_{\mathrm{s}}=\right.$ $\left.z_{0}\right)$. The full width at half maximum (FWHM) of the $q_{0}\left(z_{\mathrm{s}}\right)$ is equal to $2 z_{\mathrm{R}}$. The peak value and the FWHM of the plot provides the values for $Q_{0}$ and $\mathrm{z}_{\mathrm{R}}$. Equation (S10) can be used to calculate the nonlinear absorption coefficient $(\beta)$. 


$$
\beta=\frac{\lambda z_{R} Q_{0}}{2 P_{0} L_{e f f}}
$$

\section{Input file for the four positional isomers and optimised Cartesian coordinates of the}

\section{structures.}

All calculations were done on Gaussian 09, Revision D.01. Geometric optimizations were done using the Becke, three-parameter, Lee-Yang-Parr (B3LYP) functional at the 6-31G basis set. These Optimised structures were used to calculate the electronic absorption properties using the TD-DFT method. These calculations were done on the Coulomb-attenuated B3LYP functional and were also done with the $6-31 \mathrm{G}$ basis set. The Cartesian coordinates for each optimised structure follows.

DI1:

$\begin{array}{lrrr}\mathrm{C} & -3.63280300 & -2.16700900 & -0.41138300 \\ \mathrm{C} & -4.14680700 & -0.86277700 & -0.32497200 \\ \mathrm{C} & -5.52130300 & -0.64083300 & -0.27427800 \\ \mathrm{C} & -6.37156400 & -1.74550400 & -0.30950600 \\ \mathrm{C} & -5.84403800 & -3.04958000 & -0.38588500 \\ \mathrm{C} & -4.46543300 & -3.27928600 & -0.43991100 \\ \mathrm{C} & -2.17277800 & -2.01351500 & -0.44933600 \\ \mathrm{C} & -2.98191400 & 0.02264100 & -0.31450500 \\ \mathrm{H} & -7.44733300 & -1.60986100 & -0.28395600 \\ \mathrm{H} & -4.08054800 & -4.29104100 & -0.50503900 \\ \mathrm{~N} & -1.82248200 & -0.69601100 & -0.39051900 \\ \mathrm{~N} & -1.36513100 & -3.07395700 & -0.53159500 \\ \mathrm{~N} & -3.11506800 & 1.35058600 & -0.23851200 \\ \mathrm{C} & -2.09959000 & 2.18953300 & -0.22948100 \\ \mathrm{C} & -2.20067500 & 3.63797800 & -0.14945900 \\ \mathrm{C} & -0.88745800 & 4.15685800 & -0.17074900 \\ \mathrm{C} & -3.31993600 & 4.46818400 & -0.05963400 \\ \mathrm{C} & 0.02878100 & 3.03834500 & -0.26357200 \\ \mathrm{C} & -0.67090400 & 5.53811400 & -0.10285900 \\ \mathrm{C} & -3.08742400 & 5.84132800 & 0.00139300 \\ \mathrm{H} & -4.32071400 & 4.05454600 & -0.03557700 \\ \mathrm{C} & -1.77521900 & 6.37077000 & -0.01904600 \\ \mathrm{H} & -1.66419600 & 7.44898000 & 0.03427500 \\ \mathrm{~N} & -0.75313400 & 1.90280200 & -0.29373600 \\ \mathrm{H} & -0.37866400 & 0.96280900 & -0.35585000 \\ \mathrm{C} & -0.04974800 & -2.99148300 & -0.57359700 \\ \mathrm{C} & 0.86644200 & -4.11007500 & -0.66564300 \\ \mathrm{C} & 2.17967800 & -3.59128200 & -0.68713300\end{array}$




\begin{tabular}{|c|c|c|c|}
\hline $\mathrm{C}$ & 0.64971600 & -5.49129600 & -0.73391900 \\
\hline $\mathrm{C}$ & 2.07859700 & -2.14278500 & -0.60808100 \\
\hline $\mathrm{C}$ & 3.29886700 & -4.42158300 & -0.77740600 \\
\hline $\mathrm{C}$ & 1.75391400 & -6.32402800 & -0.81803600 \\
\hline $\mathrm{C}$ & 3.06617000 & -5.79467000 & -0.83868200 \\
\hline $\mathrm{H}$ & 4.29966100 & -4.00802400 & -0.80216500 \\
\hline $\mathrm{N}$ & 0.73214100 & -1.85601600 & -0.54320000 \\
\hline $\mathrm{H}$ & 0.35772400 & -0.91595500 & -0.48177900 \\
\hline $\mathrm{N}$ & 1.34406600 & 3.12095400 & -0.30778700 \\
\hline $\mathrm{N}$ & 3.09384500 & -1.30360700 & -0.60202800 \\
\hline $\mathrm{C}$ & 2.96046300 & 0.02445300 & -0.52818500 \\
\hline $\mathrm{C}$ & 4.12505400 & 0.91026600 & -0.52814900 \\
\hline $\mathrm{C}$ & 3.61134400 & 2.21455500 & -0.44172000 \\
\hline $\mathrm{C}$ & 5.49890000 & 0.68837300 & -0.59636700 \\
\hline $\mathrm{C}$ & 2.15169100 & 2.06065500 & -0.39261600 \\
\hline $\mathrm{C}$ & 4.44461500 & 3.32664400 & -0.41136200 \\
\hline $\mathrm{C}$ & 6.34883900 & 1.79339400 & -0.57421000 \\
\hline $\mathrm{C}$ & 5.82239800 & 3.09662000 & -0.47699900 \\
\hline $\mathrm{H}$ & 7.42345500 & 1.66000400 & -0.63689700 \\
\hline $\mathrm{N}$ & 1.80137100 & 0.74288600 & -0.44622400 \\
\hline $\mathrm{H}$ & 4.06021100 & 4.33838100 & -0.34306900 \\
\hline $\mathrm{H}$ & -0.35810400 & -5.89346100 & -0.71866700 \\
\hline $\mathrm{H}$ & -5.92051700 & 0.36724300 & -0.21809700 \\
\hline $\mathrm{H}$ & 0.33684700 & 5.94043000 & -0.11865200 \\
\hline $\mathrm{H}$ & 5.89675600 & -0.31882600 & -0.67378000 \\
\hline $\mathrm{C}$ & -5.40737700 & 6.43817900 & -0.11033300 \\
\hline $\mathrm{C}$ & -6.31644600 & 6.55875000 & 0.93392100 \\
\hline $\mathrm{C}$ & -5.84477100 & 6.07053200 & -1.38418400 \\
\hline $\mathrm{C}$ & -7.67167900 & 6.30788200 & 0.70300300 \\
\hline $\mathrm{H}$ & -5.96126300 & 6.85403700 & 1.91634100 \\
\hline $\mathrm{C}$ & -7.19732100 & 5.81729600 & -1.59319200 \\
\hline $\mathrm{H}$ & -5.13143600 & 5.98960800 & -2.19870400 \\
\hline $\mathrm{C}$ & -8.14549300 & 5.92832700 & -0.55981300 \\
\hline $\mathrm{H}$ & -8.35802500 & 6.41245600 & 1.53565800 \\
\hline $\mathrm{H}$ & -7.51741800 & 5.53299400 & -2.59150600 \\
\hline $\mathrm{O}$ & -4.08130800 & 6.78094000 & 0.12414200 \\
\hline $\mathrm{C}$ & -7.88089400 & -4.22050500 & 0.13228500 \\
\hline $\mathrm{C}$ & -8.07976800 & -3.81262200 & 1.45031900 \\
\hline $\mathrm{C}$ & -8.93086500 & -4.79673800 & -0.58358700 \\
\hline $\mathrm{C}$ & -9.33619900 & -3.97331500 & 2.03892800 \\
\hline $\mathrm{H}$ & -7.26134600 & -3.37701300 & 2.01471900 \\
\hline $\mathrm{C}$ & -10.17271700 & -4.95623000 & 0.02413900 \\
\hline $\mathrm{H}$ & -8.75882700 & -5.11674000 & -1.60658500 \\
\hline $\mathrm{C}$ & -10.41234400 & -4.54653300 & 1.34736900 \\
\hline $\mathrm{H}$ & -9.45964500 & -3.64645200 & 3.06546400 \\
\hline $\mathrm{H}$ & -10.97306200 & -5.40835500 & -0.55494700 \\
\hline $\mathrm{O}$ & -6.64751100 & -4.16491900 & -0.49252700 \\
\hline $\mathrm{C}$ & 7.88630100 & 4.21056700 & 0.04675600 \\
\hline $\mathrm{C}$ & 8.14013100 & 3.68410200 & 1.31229100 \\
\hline $\mathrm{C}$ & 8.90932500 & 4.84054300 & -0.66264400 \\
\hline
\end{tabular}




\begin{tabular}{|c|c|c|c|}
\hline $\mathrm{C}$ & 9.42348500 & 3.78212600 & 1.85438600 \\
\hline $\mathrm{H}$ & 7.34317800 & 3.20493300 & 1.87209700 \\
\hline $\mathrm{C}$ & 10.17956500 & 4.93488000 & -0.10141400 \\
\hline $\mathrm{H}$ & 8.69502300 & 5.25211300 & -1.64408900 \\
\hline $\mathrm{C}$ & 10.47402600 & 4.40640600 & 1.16765600 \\
\hline $\mathrm{H}$ & 9.58917300 & 3.36399500 & 2.84111400 \\
\hline $\mathrm{H}$ & 10.95810100 & 5.42999600 & -0.67522600 \\
\hline $\mathrm{O}$ & 6.62458000 & 4.21755700 & -0.52171200 \\
\hline $\mathrm{C}$ & -11.80689900 & -4.73565900 & 1.97093300 \\
\hline $\mathrm{C}$ & -12.18048300 & -6.23707600 & 1.95830400 \\
\hline $\mathrm{H}$ & -13.17660500 & -6.38691400 & 2.39261500 \\
\hline $\mathrm{H}$ & -12.19678400 & -6.64559800 & 0.94232700 \\
\hline $\mathrm{H}$ & -11.46284300 & -6.82420300 & 2.54255300 \\
\hline $\mathrm{C}$ & -12.85051300 & -3.94227800 & 1.14881600 \\
\hline $\mathrm{H}$ & -13.85273900 & -4.07197900 & 1.57559900 \\
\hline $\mathrm{H}$ & -12.61698900 & -2.87139200 & 1.14884900 \\
\hline $\mathrm{H}$ & -12.88680400 & -4.27572100 & 0.10632700 \\
\hline $\mathrm{C}$ & -11.86850100 & -4.24028900 & 3.42848100 \\
\hline $\mathrm{H}$ & -11.16834900 & -4.78284400 & 4.07397600 \\
\hline $\mathrm{H}$ & -11.64693300 & -3.16965100 & 3.50651500 \\
\hline $\mathrm{H}$ & -12.87611800 & -4.39775400 & 3.82920200 \\
\hline $\mathrm{C}$ & -9.63047200 & 5.64013900 & -0.84603200 \\
\hline $\mathrm{C}$ & -9.78557900 & 4.18515600 & -1.34919900 \\
\hline $\mathrm{H}$ & -10.83859700 & 3.96670500 & -1.56463600 \\
\hline $\mathrm{H}$ & -9.21475600 & 4.00666800 & -2.26664100 \\
\hline $\mathrm{H}$ & -9.43737700 & 3.47018400 & -0.59502000 \\
\hline $\mathrm{C}$ & -10.14515100 & 6.61506300 & -1.93182500 \\
\hline $\mathrm{H}$ & -11.20281600 & 6.42091200 & -2.14795600 \\
\hline $\mathrm{H}$ & -10.05099600 & 7.65547900 & -1.60058100 \\
\hline $\mathrm{H}$ & -9.58991100 & 6.51167400 & -2.86995600 \\
\hline $\mathrm{C}$ & -10.51060200 & 5.81059000 & 0.40674800 \\
\hline $\mathrm{H}$ & -10.21452500 & 5.12618400 & 1.20996000 \\
\hline $\mathrm{H}$ & -10.47212400 & 6.83408700 & 0.79685500 \\
\hline $\mathrm{H}$ & -11.55481700 & 5.59271900 & 0.15621700 \\
\hline $\mathrm{C}$ & 11.89741100 & 4.52752000 & 1.74133000 \\
\hline $\mathrm{C}$ & 12.28814300 & 6.02113300 & 1.84556900 \\
\hline $\mathrm{H}$ & 13.30431100 & 6.12371100 & 2.24581100 \\
\hline $\mathrm{H}$ & 12.26387700 & 6.51852200 & 0.87026800 \\
\hline $\mathrm{H}$ & 11.60398600 & 6.55926100 & 2.51149100 \\
\hline $\mathrm{C}$ & 12.89315900 & 3.80296900 & 0.80452100 \\
\hline $\mathrm{H}$ & 13.91555300 & 3.88873400 & 1.19277200 \\
\hline $\mathrm{H}$ & 12.64882600 & 2.73769500 & 0.72180500 \\
\hline $\mathrm{H}$ & 12.88406800 & 4.22647000 & -0.20537200 \\
\hline $\mathrm{C}$ & 12.01807500 & 3.90263600 & 3.14417900 \\
\hline $\mathrm{H}$ & 11.35727800 & 4.39339700 & 3.86787400 \\
\hline $\mathrm{H}$ & 11.78266700 & 2.83222900 & 3.13585500 \\
\hline $\mathrm{H}$ & 13.04557000 & 4.01103700 & 3.50915400 \\
\hline $\mathrm{O}$ & 4.05984600 & -6.73446700 & -0.96160600 \\
\hline $\mathrm{C}$ & 5.38642800 & -6.39076700 & -0.73139500 \\
\hline $\mathrm{C}$ & 5.82797500 & -6.02712700 & 0.54214900 \\
\hline
\end{tabular}




$\begin{array}{lccc}\mathrm{C} & 6.29177200 & -6.50630500 & -1.77944400 \\ \mathrm{C} & 7.18098900 & -5.77308500 & 0.74719400 \\ \mathrm{H} & 5.11739000 & -5.95014700 & 1.35946000 \\ \mathrm{C} & 7.64753100 & -6.25462300 & -1.55255200 \\ \mathrm{H} & 5.93339100 & -6.79835600 & -2.76166200 \\ \mathrm{C} & 8.12548700 & -5.87928600 & -0.29003800 \\ \mathrm{H} & 7.50450100 & -5.49215000 & 1.74537200 \\ \mathrm{H} & 8.33094100 & -6.35516000 & -2.38809000 \\ \mathrm{C} & 9.61122200 & -5.59072200 & -0.00809600 \\ \mathrm{C} & 9.76682000 & -4.13718900 & 0.49908600 \\ \mathrm{H} & 9.41530400 & -3.42013400 & -0.25154900 \\ \mathrm{H} & 9.19906400 & -3.96225500 & 1.41915100 \\ \mathrm{H} & 10.82043400 & -3.91849500 & 0.71141800 \\ \mathrm{C} & 10.13044600 & -6.56857700 & 1.07288300 \\ \mathrm{H} & 10.03573000 & -7.60803600 & 0.73883000 \\ \mathrm{H} & 11.18879000 & -6.37443800 & 1.28571400 \\ \mathrm{H} & 9.57854400 & -6.46838200 & 2.01334600 \\ \mathrm{C} & 10.48719400 & -5.75650700 & -1.26442000 \\ \mathrm{H} & 10.44810900 & -6.77877500 & -1.65766600 \\ \mathrm{H} & 10.18796300 & -5.06976300 & -2.06443800 \\ \mathrm{H} & 11.53211800 & -5.53870000 & -1.01678800 \\ \mathrm{H} & 1.64280300 & -7.40220100 & -0.87192800\end{array}$

DI2:

$\begin{array}{lrrr}\mathrm{C} & -4.10672300 & 1.05386200 & -0.38637600 \\ \mathrm{C} & -3.53057300 & 2.32991000 & -0.49572600 \\ \mathrm{C} & -4.32967300 & 3.47028700 & -0.54678700 \\ \mathrm{C} & -5.71332900 & 3.31148900 & -0.48145000 \\ \mathrm{C} & -6.27904400 & 2.02723300 & -0.35654600 \\ \mathrm{C} & -5.48364000 & 0.87830700 & -0.31081200 \\ \mathrm{C} & -2.97975000 & 0.11317000 & -0.36735700 \\ \mathrm{C} & -2.08398500 & 2.11032100 & -0.53422300 \\ \mathrm{H} & -6.36736600 & 4.17546200 & -0.53003800 \\ \mathrm{H} & -5.93948800 & -0.10170600 & -0.22188400 \\ \mathrm{~N} & -1.79183100 & 0.77720800 & -0.45633100 \\ \mathrm{~N} & -3.17705500 & -1.20514700 & -0.27490400 \\ \mathrm{~N} & -1.22582200 & 3.12989100 & -0.62982800 \\ \mathrm{C} & 0.08424800 & 2.98562900 & -0.66521300 \\ \mathrm{C} & 1.05234300 & 4.05952500 & -0.76247000 \\ \mathrm{C} & 2.34017900 & 3.48009900 & -0.76911300 \\ \mathrm{C} & 0.90178500 & 5.44869200 & -0.84428600 \\ \mathrm{C} & 2.17121800 & 2.03911600 & -0.67641600 \\ \mathrm{C} & 3.49799300 & 4.25581000 & -0.85665700 \\ \mathrm{C} & 2.04466800 & 6.22795100 & -0.92560000 \\ \mathrm{H} & -0.08592300 & 5.89825200 & -0.84070600 \\ \mathrm{C} & 3.33102100 & 5.63789300 & -0.93015500 \\ \mathrm{~N} & 0.81264400 & 1.81540600 & -0.61855900 \\ \mathrm{H} & 0.39447600 & 0.89448800 & -0.54971900 \\ \mathrm{C} & -2.20215300 & -2.09090200 & -0.25592300 \\ \mathrm{C} & -2.37118800 & -3.53197100 & -0.16482400\end{array}$




\begin{tabular}{|c|c|c|c|}
\hline $\mathrm{C}$ & -1.08353200 & -4.11172900 & -0.17649300 \\
\hline $\mathrm{C}$ & -3.52890900 & -4.30753200 & -0.07518400 \\
\hline $\mathrm{C}$ & -0.11547100 & -3.03787700 & -0.27475200 \\
\hline $\mathrm{C}$ & -0.93308500 & -5.50107000 & -0.09763000 \\
\hline $\mathrm{C}$ & -3.36209300 & -5.68980000 & -0.00469600 \\
\hline $\mathrm{C}$ & -2.07593600 & -6.28018400 & -0.01418900 \\
\hline $\mathrm{H}$ & 0.05447500 & -5.95090000 & -0.10552600 \\
\hline $\mathrm{N}$ & -0.84369800 & -1.86745200 & -0.31778800 \\
\hline $\mathrm{H}$ & -0.42548500 & -0.94658700 & -0.38710800 \\
\hline $\mathrm{N}$ & 3.14633200 & 1.15363400 & -0.65287500 \\
\hline $\mathrm{N}$ & 1.19451900 & -3.18225500 & -0.31231100 \\
\hline $\mathrm{C}$ & 2.05275500 & -2.16251500 & -0.40538200 \\
\hline $\mathrm{C}$ & 3.49933000 & -2.38211200 & -0.44214000 \\
\hline $\mathrm{C}$ & 4.07598400 & -1.10561800 & -0.54361100 \\
\hline $\mathrm{C}$ & 4.29775400 & -3.52328200 & -0.40001600 \\
\hline $\mathrm{C}$ & 2.94897500 & -0.16482900 & -0.56292700 \\
\hline $\mathrm{C}$ & 5.45377200 & -0.92874300 & -0.59694000 \\
\hline $\mathrm{C}$ & 5.68161200 & -3.36432800 & -0.45911800 \\
\hline $\mathrm{C}$ & 6.24880100 & -2.07799400 & -0.55103600 \\
\hline $\mathrm{H}$ & 6.33472200 & -4.23014300 & -0.43967300 \\
\hline $\mathrm{N}$ & 1.76079800 & -0.82910700 & -0.47884100 \\
\hline $\mathrm{H}$ & 5.91026500 & 0.05198100 & -0.67391300 \\
\hline $\mathrm{H}$ & -4.50899500 & -3.84649600 & -0.05949100 \\
\hline $\mathrm{H}$ & -3.88676200 & 4.45673800 & -0.64373900 \\
\hline $\mathrm{H}$ & 4.47820800 & 3.79495500 & -0.86904700 \\
\hline $\mathrm{H}$ & 3.85356200 & -4.51154300 & -0.33161400 \\
\hline $\mathrm{C}$ & -8.49925200 & 2.71526500 & 0.26473500 \\
\hline $\mathrm{C}$ & -8.22186400 & 3.30523700 & 1.49693600 \\
\hline $\mathrm{C}$ & -9.72740400 & 2.94821900 & -0.35602500 \\
\hline $\mathrm{C}$ & -9.17321700 & 4.13693600 & 2.09206000 \\
\hline $\mathrm{H}$ & -7.27420100 & 3.11653000 & 1.99097500 \\
\hline $\mathrm{C}$ & -10.66554600 & 3.77203000 & 0.25864700 \\
\hline $\mathrm{H}$ & -9.93291900 & 2.47618100 & -1.31182000 \\
\hline $\mathrm{C}$ & -10.41501000 & 4.39329300 & 1.49481100 \\
\hline $\mathrm{H}$ & -8.92649100 & 4.58137600 & 3.04994100 \\
\hline $\mathrm{H}$ & -11.61376300 & 3.93389800 & -0.24665500 \\
\hline $\mathrm{O}$ & -7.64326100 & 1.82331800 & -0.35592000 \\
\hline $\mathrm{C}$ & 8.50903900 & -2.70136300 & -0.02146100 \\
\hline $\mathrm{C}$ & 8.34849100 & -3.08405600 & 1.30933600 \\
\hline $\mathrm{C}$ & 9.66041500 & -3.07166900 & -0.71738800 \\
\hline $\mathrm{C}$ & 9.33974800 & -3.84653000 & 1.93120500 \\
\hline $\mathrm{H}$ & 7.45996600 & -2.78747500 & 1.85759800 \\
\hline $\mathrm{C}$ & 10.64035000 & -3.82422200 & -0.07674800 \\
\hline $\mathrm{H}$ & 9.77445500 & -2.76150400 & -1.75148400 \\
\hline $\mathrm{C}$ & 10.50756000 & -4.23583200 & 1.26088500 \\
\hline $\mathrm{H}$ & 9.18588400 & -4.12878300 & 2.96673900 \\
\hline $\mathrm{H}$ & 11.52662000 & -4.09936600 & -0.64170000 \\
\hline $\mathrm{O}$ & 7.60830000 & -1.88429000 & -0.68165800 \\
\hline $\mathrm{C}$ & -11.48156600 & 5.30101500 & 2.13375100 \\
\hline $\mathrm{C}$ & -12.76963400 & 4.48237600 & 2.38849800 \\
\hline
\end{tabular}




\begin{tabular}{|c|c|c|c|}
\hline $\mathrm{H}$ & -13.54321500 & 5.11599900 & 2.83966100 \\
\hline $\mathrm{H}$ & -13.17846200 & 4.06709700 & 1.46131000 \\
\hline $\mathrm{H}$ & -12.57435800 & 3.64668400 & 3.07018900 \\
\hline $\mathrm{C}$ & -11.80222700 & 6.47475800 & 1.17817300 \\
\hline $\mathrm{H}$ & -12.56515400 & 7.12882700 & 1.61804500 \\
\hline $\mathrm{H}$ & -10.90780400 & 7.07800200 & 0.98517100 \\
\hline $\mathrm{H}$ & -12.18239000 & 6.12295800 & 0.21338700 \\
\hline $\mathrm{C}$ & -11.01595200 & 5.89264400 & 3.47782600 \\
\hline $\mathrm{H}$ & -10.80170200 & 5.11167800 & 4.21627000 \\
\hline $\mathrm{H}$ & -10.11770700 & 6.51000400 & 3.36215200 \\
\hline $\mathrm{H}$ & -11.80410200 & 6.53094000 & 3.89283100 \\
\hline $\mathrm{C}$ & 11.61658600 & -5.07324700 & 1.92379300 \\
\hline $\mathrm{C}$ & 12.94396400 & -4.27836100 & 1.90504100 \\
\hline $\mathrm{H}$ & 13.74765700 & -4.86439400 & 2.36753300 \\
\hline $\mathrm{H}$ & 13.25711800 & -4.03146800 & 0.88511900 \\
\hline $\mathrm{H}$ & 12.84539000 & -3.33860900 & 2.46028200 \\
\hline $\mathrm{C}$ & 11.80177900 & -6.39580600 & 1.14240200 \\
\hline $\mathrm{H}$ & 12.59444200 & -7.00168000 & 1.59839800 \\
\hline $\mathrm{H}$ & 10.87824600 & -6.98592200 & 1.14588400 \\
\hline $\mathrm{H}$ & 12.07905700 & -6.21676600 & 0.09821900 \\
\hline $\mathrm{C}$ & 11.28892500 & -5.42382600 & 3.38772900 \\
\hline $\mathrm{H}$ & 11.17517400 & -4.52682200 & 4.00717600 \\
\hline $\mathrm{H}$ & 10.36998700 & -6.01551800 & 3.47027000 \\
\hline $\mathrm{H}$ & 12.10352400 & -6.01869500 & 3.81600100 \\
\hline $\mathrm{C}$ & -5.70596400 & -6.18038800 & -0.13727300 \\
\hline $\mathrm{C}$ & -6.63617000 & -6.26875800 & 0.89137400 \\
\hline $\mathrm{C}$ & -6.10662300 & -5.78668300 & -1.41541300 \\
\hline $\mathrm{C}$ & -7.97557900 & -5.95909500 & 0.64052800 \\
\hline $\mathrm{H}$ & -6.30984200 & -6.58451000 & 1.87743400 \\
\hline $\mathrm{C}$ & -7.44349400 & -5.47404700 & -1.64391700 \\
\hline $\mathrm{H}$ & -5.37767900 & -5.73062300 & -2.21810500 \\
\hline $\mathrm{C}$ & -8.41234700 & -5.55124200 & -0.62673400 \\
\hline $\mathrm{H}$ & -8.67886400 & -6.03950800 & 1.46155400 \\
\hline $\mathrm{H}$ & -7.73463200 & -5.16854500 & -2.64482300 \\
\hline $\mathrm{C}$ & -9.87854000 & -5.19686300 & -0.93469100 \\
\hline $\mathrm{C}$ & -10.41655600 & -6.14155200 & -2.03590700 \\
\hline $\mathrm{H}$ & -11.46096700 & -5.90004700 & -2.26816700 \\
\hline $\mathrm{H}$ & -9.84163700 & -6.05617000 & -2.96393900 \\
\hline $\mathrm{H}$ & -10.37338900 & -7.18732400 & -1.71087000 \\
\hline $\mathrm{C}$ & -10.78600300 & -5.33742300 & 0.30220200 \\
\hline $\mathrm{H}$ & -10.47441300 & -4.67168900 & 1.11515100 \\
\hline $\mathrm{H}$ & -11.81526600 & -5.07233200 & 0.03573200 \\
\hline $\mathrm{H}$ & -10.79845400 & -6.36431900 & 0.68506500 \\
\hline $\mathrm{C}$ & -9.96180700 & -3.73325600 & -1.42990600 \\
\hline $\mathrm{H}$ & -9.59685900 & -3.03812900 & -0.66537500 \\
\hline $\mathrm{H}$ & -9.36734900 & -3.57442100 & -2.33578400 \\
\hline $\mathrm{H}$ & -11.00045300 & -3.46845700 & -1.66251600 \\
\hline $\mathrm{O}$ & -4.39955900 & -6.58041500 & 0.11795100 \\
\hline $\mathrm{H}$ & -2.01605100 & -7.36206600 & 0.04653700 \\
\hline $\mathrm{O}$ & 4.36848600 & 6.52874100 & -1.05103500 \\
\hline
\end{tabular}




$\begin{array}{cccc}\mathrm{C} & 5.67480500 & 6.12843400 & -0.79581200 \\ \mathrm{C} & 6.60440800 & 6.21314400 & -1.82530300 \\ \mathrm{C} & 6.07596900 & 5.73801500 & 0.48316500 \\ \mathrm{C} & 7.94372100 & 5.90311500 & -1.57443200 \\ \mathrm{H} & 6.27771100 & 6.52630600 & -2.81206100 \\ \mathrm{C} & 7.41274700 & 5.42495600 & 0.71172700 \\ \mathrm{H} & 5.34741000 & 5.68492200 & 1.28642200 \\ \mathrm{C} & 8.38100100 & 5.49852000 & -0.30629900 \\ \mathrm{H} & 8.64650800 & 5.98061200 & -2.39615200 \\ \mathrm{H} & 7.70437500 & 5.12206100 & 1.71329500 \\ \mathrm{C} & 9.84708200 & 5.14365800 & 0.00166200 \\ \mathrm{C} & 10.75393400 & 5.28043500 & -1.23610600 \\ \mathrm{H} & 10.76714100 & 6.30640500 & -1.62141800 \\ \mathrm{H} & 11.78308500 & 5.01495200 & -0.96960600 \\ \mathrm{H} & 10.44120200 & 4.61310100 & -2.04730500 \\ \mathrm{C} & 9.92933500 & 3.68121000 & 0.50042400 \\ \mathrm{H} & 9.33542300 & 3.52525800 & 1.40716600 \\ \mathrm{H} & 9.56308000 & 2.98450600 & -0.26203600 \\ \mathrm{H} & 10.96780500 & 3.41575600 & 0.73295500 \\ \mathrm{C} & 10.38659200 & 6.09058000 & 1.10022400 \\ \mathrm{H} & 11.43092200 & 5.84869800 & 1.33243800 \\ \mathrm{H} & 10.34414400 & 7.13559600 & 0.77266600 \\ \mathrm{H} & 9.81217700 & 6.00794200 & 2.02882400 \\ \mathrm{H} & 1.98468200 & 7.30968500 & -0.98881100\end{array}$

DI3:

$\begin{array}{lrrr}\mathrm{C} & 5.67314700 & -0.11555500 & 0.07961000 \\ \mathrm{C} & 5.50073600 & -1.52388600 & 0.09995100 \\ \mathrm{C} & 6.56463800 & -2.38364600 & 0.17669300 \\ \mathrm{C} & 7.91477900 & -1.82345500 & 0.23969500 \\ \mathrm{C} & 8.04971100 & -0.36488200 & 0.22001800 \\ \mathrm{C} & 6.96056200 & 0.46597300 & 0.14114000 \\ \mathrm{C} & 4.34886500 & 0.43910200 & -0.00839600 \\ \mathrm{C} & 4.04320400 & -1.73902300 & 0.02287200 \\ \mathrm{H} & 7.06775700 & 1.54663300 & 0.12640400 \\ \mathrm{~N} & 3.38906400 & -0.55812400 & -0.04022700 \\ \mathrm{~N} & 4.13932600 & 1.76335000 & -0.05165000 \\ \mathrm{~N} & 3.52698700 & -2.97615600 & 0.02328100 \\ \mathrm{C} & 2.23725400 & -3.22489900 & -0.03964300 \\ \mathrm{C} & 1.62583600 & -4.54119800 & -0.03938400 \\ \mathrm{C} & 0.22800400 & -4.36751300 & -0.11536100 \\ \mathrm{C} & 2.17704300 & -5.82543500 & 0.01934200 \\ \mathrm{C} & -0.03236500 & -2.93584900 & -0.16518000 \\ \mathrm{C} & -0.65172800 & -5.45016600 & -0.13358600 \\ \mathrm{C} & 1.31333400 & -6.90961900 & 0.00126700 \\ \mathrm{H} & 3.25170600 & -5.96409100 & 0.07742200 \\ \mathrm{C} & -0.08732200 & -6.72542700 & -0.07365700 \\ \mathrm{~N} & 1.19927500 & -2.31869100 & -0.11609700 \\ \mathrm{H} & 1.32652100 & -1.31331700 & -0.13384100\end{array}$




\begin{tabular}{|c|c|c|c|}
\hline $\mathrm{C}$ & 2.95247100 & 2.31781500 & -0.13424800 \\
\hline $\mathrm{C}$ & 2.68524500 & 3.74382800 & -0.18664400 \\
\hline $\mathrm{C}$ & 1.28853600 & 3.91864800 & -0.27215200 \\
\hline $\mathrm{C}$ & 3.53664300 & 4.85353900 & -0.16767100 \\
\hline $\mathrm{C}$ & 0.68072100 & 2.59497300 & -0.27337000 \\
\hline $\mathrm{C}$ & 0.70416500 & 5.18391800 & -0.34087300 \\
\hline $\mathrm{C}$ & 2.96808000 & 6.11615600 & -0.23301100 \\
\hline $\mathrm{C}$ & 1.56568000 & 6.28125400 & -0.31833700 \\
\hline $\mathrm{H}$ & -0.37055700 & 5.29882200 & -0.41001400 \\
\hline $\mathrm{H}$ & 3.58264100 & 7.01049100 & -0.22095100 \\
\hline $\mathrm{N}$ & 1.71793600 & 1.69518600 & -0.18955300 \\
\hline $\mathrm{H}$ & 1.59360600 & 0.68957200 & -0.17117000 \\
\hline $\mathrm{N}$ & -1.22119400 & -2.37685400 & -0.24313100 \\
\hline $\mathrm{N}$ & -0.61188800 & 2.35168000 & -0.34118200 \\
\hline $\mathrm{C}$ & -1.13735600 & 1.12172300 & -0.33744500 \\
\hline $\mathrm{C}$ & -2.58288700 & 0.90881300 & -0.41356300 \\
\hline $\mathrm{C}$ & -2.76462500 & -0.48335200 & -0.38360700 \\
\hline $\mathrm{C}$ & -3.67541700 & 1.76791600 & -0.50420400 \\
\hline $\mathrm{C}$ & -1.41471100 & -1.05425200 & -0.29094100 \\
\hline $\mathrm{C}$ & -4.02894700 & -1.05617800 & -0.43219700 \\
\hline $\mathrm{C}$ & -4.95262000 & 1.21003200 & -0.56067500 \\
\hline $\mathrm{C}$ & -5.12329100 & -0.18749700 & -0.51861300 \\
\hline $\mathrm{H}$ & -5.82602800 & 1.84770000 & -0.64284900 \\
\hline $\mathrm{N}$ & -0.47127500 & -0.06968800 & -0.26615000 \\
\hline $\mathrm{H}$ & -4.18173900 & -2.12951100 & -0.40784600 \\
\hline $\mathrm{H}$ & 4.61209900 & 4.72457800 & -0.10209900 \\
\hline $\mathrm{H}$ & 6.45192400 & -3.46273600 & 0.19236700 \\
\hline $\mathrm{H}$ & -1.72267400 & -5.29907300 & -0.19143900 \\
\hline $\mathrm{H}$ & -3.53604300 & 2.84400700 & -0.53897300 \\
\hline $\mathrm{C}$ & -0.21239800 & 7.88197700 & -0.34899300 \\
\hline $\mathrm{C}$ & -0.89217400 & 7.89515300 & 0.86478200 \\
\hline $\mathrm{C}$ & -0.86366500 & 8.24742300 & -1.52514500 \\
\hline $\mathrm{C}$ & -2.23693400 & 8.27163400 & 0.89568800 \\
\hline $\mathrm{H}$ & -0.37104100 & 7.61963100 & 1.77665700 \\
\hline $\mathrm{C}$ & -2.20375500 & 8.62412300 & -1.47434700 \\
\hline $\mathrm{H}$ & -0.31644800 & 8.24078800 & -2.46272800 \\
\hline $\mathrm{C}$ & -2.92519400 & 8.64404700 & -0.26794900 \\
\hline $\mathrm{H}$ & -2.74251300 & 8.27506200 & 1.85458200 \\
\hline $\mathrm{H}$ & -2.69418800 & 8.90794200 & -2.40094700 \\
\hline $\mathrm{O}$ & 1.14690100 & 7.58485300 & -0.39511300 \\
\hline $\mathrm{C}$ & -7.49818200 & -0.18266200 & -0.13110200 \\
\hline $\mathrm{C}$ & -7.54852000 & 0.39170900 & 1.13785000 \\
\hline $\mathrm{C}$ & -8.65276200 & -0.25133600 & -0.91120000 \\
\hline $\mathrm{C}$ & -8.75699900 & 0.90659300 & 1.61254000 \\
\hline $\mathrm{H}$ & -6.65537000 & 0.43326000 & 1.75320800 \\
\hline $\mathrm{C}$ & -9.84901000 & 0.25939500 & -0.41596200 \\
\hline $\mathrm{H}$ & -8.59933400 & -0.70850500 & -1.89437100 \\
\hline $\mathrm{C}$ & -9.93495600 & 0.85551600 & 0.85437300 \\
\hline $\mathrm{H}$ & -8.76474000 & 1.34713200 & 2.60318700 \\
\hline $\mathrm{H}$ & -10.73381000 & 0.19250600 & -1.04268800 \\
\hline
\end{tabular}




\begin{tabular}{|c|c|c|c|}
\hline $\mathrm{O}$ & -6.35841600 & -0.78445800 & -0.63801400 \\
\hline $\mathrm{C}$ & -11.28007900 & 1.41274600 & 1.35492000 \\
\hline $\mathrm{C}$ & -12.32503500 & 0.27262700 & 1.40478100 \\
\hline $\mathrm{H}$ & -13.29158400 & 0.65565000 & 1.75459100 \\
\hline $\mathrm{H}$ & -12.48352300 & -0.17918700 & 0.41991700 \\
\hline $\mathrm{H}$ & -12.00626400 & -0.52198300 & 2.08894600 \\
\hline $\mathrm{C}$ & -11.77399900 & 2.51593000 & 0.38876300 \\
\hline $\mathrm{H}$ & -12.73604900 & 2.91824600 & 0.72897600 \\
\hline $\mathrm{H}$ & -11.05751900 & 3.34384800 & 0.33975900 \\
\hline $\mathrm{H}$ & -11.91434700 & 2.13486100 & -0.62826800 \\
\hline $\mathrm{C}$ & -11.17139900 & 2.02488200 & 2.76435700 \\
\hline $\mathrm{H}$ & -10.85420600 & 1.28510500 & 3.50818300 \\
\hline $\mathrm{H}$ & -10.46561800 & 2.86301400 & 2.79213000 \\
\hline $\mathrm{H}$ & -12.14963100 & 2.40714000 & 3.07667800 \\
\hline $\mathrm{C}$ & -4.40632100 & 9.06501600 & -0.26592300 \\
\hline $\mathrm{C}$ & -5.21315000 & 8.11091300 & -1.17871900 \\
\hline $\mathrm{H}$ & -6.27210700 & 8.39630700 & -1.18717900 \\
\hline $\mathrm{H}$ & -4.85448600 & 8.13427700 & -2.21315200 \\
\hline $\mathrm{H}$ & -5.14276800 & 7.07632200 & -0.82389700 \\
\hline $\mathrm{C}$ & -4.53264000 & 10.51222100 & -0.79846800 \\
\hline $\mathrm{H}$ & -5.58408600 & 10.82412500 & -0.80715300 \\
\hline $\mathrm{H}$ & -3.97561500 & 11.21298900 & -0.16630900 \\
\hline $\mathrm{H}$ & -4.14962700 & 10.60713100 & -1.82003100 \\
\hline $\mathrm{C}$ & -5.02555100 & 9.01784500 & 1.14400200 \\
\hline $\mathrm{H}$ & -4.99384900 & 8.00920000 & 1.57164400 \\
\hline $\mathrm{H}$ & -4.51807300 & 9.69985200 & 1.83569600 \\
\hline $\mathrm{H}$ & -6.07708200 & 9.32168000 & 1.09489400 \\
\hline $\mathrm{C}$ & -2.20701300 & -7.82714300 & -0.14712900 \\
\hline $\mathrm{C}$ & -2.95399100 & -7.80141900 & 1.02508000 \\
\hline $\mathrm{C}$ & -2.84138400 & -7.87559300 & -1.38727000 \\
\hline $\mathrm{C}$ & -4.34920500 & -7.81837100 & 0.95212100 \\
\hline $\mathrm{H}$ & -2.44622400 & -7.77592400 & 1.98446600 \\
\hline $\mathrm{C}$ & -4.23284500 & -7.89322200 & -1.44052400 \\
\hline $\mathrm{H}$ & -2.24482200 & -7.90685600 & -2.29390400 \\
\hline $\mathrm{C}$ & -5.02197000 & -7.86236000 & -0.27687900 \\
\hline $\mathrm{H}$ & -4.90844100 & -7.79889800 & 1.88042100 \\
\hline $\mathrm{H}$ & -4.70962700 & -7.93499800 & -2.41554400 \\
\hline $\mathrm{C}$ & -6.55757100 & -7.88454200 & -0.38957000 \\
\hline $\mathrm{C}$ & -7.00185100 & -9.18935300 & -1.09293400 \\
\hline $\mathrm{H}$ & -8.09425300 & -9.21807900 & -1.18701900 \\
\hline $\mathrm{H}$ & -6.57888800 & -9.27512900 & -2.09935600 \\
\hline $\mathrm{H}$ & -6.68685500 & -10.06997200 & -0.52164900 \\
\hline $\mathrm{C}$ & -7.24694300 & -7.82237800 & 0.98652200 \\
\hline $\mathrm{H}$ & -6.99098600 & -6.90557300 & 1.52966800 \\
\hline $\mathrm{H}$ & -8.33444600 & -7.83438400 & 0.85379700 \\
\hline $\mathrm{H}$ & -6.98304500 & -8.67999500 & 1.61585800 \\
\hline $\mathrm{C}$ & -7.03140100 & -6.66784000 & -1.22010200 \\
\hline $\mathrm{H}$ & -6.73699300 & -5.72656000 & -0.74229000 \\
\hline $\mathrm{H}$ & -6.61254100 & -6.67410600 & -2.23193700 \\
\hline $\mathrm{H}$ & -8.12416300 & -6.67400600 & -1.31299400 \\
\hline
\end{tabular}




$\begin{array}{lrrr}\mathrm{O} & -0.81686100 & -7.88517700 & -0.08135800 \\ \mathrm{H} & 1.68782700 & -7.92720000 & 0.04464700 \\ \mathrm{H} & 9.06141900 & 0.02552000 & 0.27170500 \\ \mathrm{O} & 9.06382900 & -2.67108500 & 0.31783800 \\ \mathrm{C} & 10.24793100 & -1.86954100 & 0.33603400 \\ \mathrm{C} & 10.77941100 & -1.43774300 & 1.55120000 \\ \mathrm{C} & 10.87187700 & -1.51988700 & -0.86181500 \\ \mathrm{C} & 11.93480000 & -0.65592400 & 1.56873300 \\ \mathrm{H} & 10.28787800 & -1.71356700 & 2.49537100 \\ \mathrm{C} & 12.02672300 & -0.73786200 & -0.84438800 \\ \mathrm{H} & 10.45283300 & -1.86082900 & -1.81974800 \\ \mathrm{C} & 12.55812000 & -0.30546600 & 0.37128800 \\ \mathrm{H} & 12.35312400 & -0.31501900 & 2.52687200 \\ \mathrm{H} & 12.51839600 & -0.46146200 & -1.78839900 \\ \mathrm{C} & 13.83296400 & 0.55824900 & 0.39048600 \\ \mathrm{C} & 13.89840500 & 1.40547700 & -0.89385200 \\ \mathrm{H} & 14.70115000 & 2.10871900 & -0.81671300 \\ \mathrm{H} & 14.06443700 & 0.76556100 & -1.73518500 \\ \mathrm{H} & 12.97509600 & 1.93080800 & -1.02202200 \\ \mathrm{C} & 13.80469800 & 1.48795900 & 1.61785700 \\ \mathrm{H} & 12.88595900 & 2.03631900 & 1.62884200 \\ \mathrm{H} & 13.88150400 & 0.90280800 & 2.51038100 \\ \mathrm{H} & 14.62699200 & 2.17071800 & 1.56713200 \\ \mathrm{C} & 15.07063200 & -0.35497300 & 0.46665000 \\ \mathrm{H} & 15.08999900 & -1.00128700 & -0.38587800 \\ \mathrm{H} & 15.95642000 & 0.24512400 & 0.47948000 \\ \mathrm{H} & 15.02541600 & -0.94326800 & 1.35926600\end{array}$

DI4:

$\begin{array}{lrrr}\mathrm{C} & -2.82216130 & -0.56439168 & -0.10012465 \\ \mathrm{C} & -2.75391712 & 0.83847948 & -0.07106540 \\ \mathrm{C} & -3.91558499 & 1.60722034 & -0.02283526 \\ \mathrm{C} & -5.14400579 & 0.94836079 & -0.00255336 \\ \mathrm{C} & -5.19907756 & -0.45952717 & -0.02193251 \\ \mathrm{C} & -4.03877664 & -1.23703668 & -0.07266452 \\ \mathrm{C} & -1.43042168 & -1.02545361 & -0.15339966 \\ \mathrm{C} & -1.32871785 & 1.16631695 & -0.10821506 \\ \mathrm{H} & -6.06957065 & 1.51349697 & 0.02340721 \\ \mathrm{H} & -4.10366430 & -2.31940237 & -0.09314070 \\ \mathrm{~N} & -0.56877154 & 0.03182174 & -0.15667116 \\ \mathrm{~N} & -1.12979289 & -2.32748212 & -0.19319095 \\ \mathrm{~N} & -0.90138154 & 2.43340407 & -0.09585057 \\ \mathrm{C} & 0.36824725 & 2.77937536 & -0.13136334 \\ \mathrm{C} & 0.87450618 & 4.14239463 & -0.12716727 \\ \mathrm{C} & 2.28434715 & 4.07201205 & -0.17746623 \\ \mathrm{C} & 0.19930793 & 5.36356015 & -0.08299440 \\ \mathrm{C} & 2.65613883 & 2.67214593 & -0.21458650 \\ \mathrm{C} & 3.05196120 & 5.24231529 & -0.18378091 \\ \mathrm{C} & 0.97780088 & 6.52006549 & -0.10048196\end{array}$




\begin{tabular}{|c|c|c|c|}
\hline $\mathrm{H}$ & -0.88234806 & 5.40120783 & -0.03665292 \\
\hline $\mathrm{C}$ & 2.39045934 & 6.45964874 & -0.14743180 \\
\hline $\mathrm{H}$ & 2.93688159 & 7.39720408 & -0.15416209 \\
\hline $\mathrm{N}$ & 1.47681576 & 1.96024521 & -0.18394015 \\
\hline $\mathrm{H}$ & 1.42893399 & 0.94772416 & -0.19985474 \\
\hline $\mathrm{C}$ & 0.10009922 & -2.79335300 & -0.24654210 \\
\hline $\mathrm{C}$ & 0.47178841 & -4.19801381 & -0.29526861 \\
\hline $\mathrm{C}$ & 1.88149888 & -4.26224340 & -0.34671200 \\
\hline $\mathrm{C}$ & -0.31962901 & -5.34824401 & -0.29448655 \\
\hline $\mathrm{C}$ & 2.38742327 & -2.90430051 & -0.33121798 \\
\hline $\mathrm{C}$ & 2.53134011 & -5.50093276 & -0.39895431 \\
\hline $\mathrm{C}$ & 0.34257553 & -6.57369945 & -0.35383479 \\
\hline $\mathrm{C}$ & 1.75491342 & -6.64864117 & -0.40378824 \\
\hline $\mathrm{H}$ & 3.61451296 & -5.55511014 & -0.43797523 \\
\hline $\mathrm{N}$ & 1.28233549 & -2.08332240 & -0.27107689 \\
\hline $\mathrm{H}$ & 1.33228219 & -1.07106379 & -0.24907603 \\
\hline $\mathrm{N}$ & 3.88875994 & 2.20395669 & -0.26784496 \\
\hline $\mathrm{N}$ & 3.65943892 & -2.55608891 & -0.36819520 \\
\hline $\mathrm{C}$ & 4.08328341 & -1.28961564 & -0.35284104 \\
\hline $\mathrm{C}$ & 5.50947680 & -0.96167427 & -0.39780305 \\
\hline $\mathrm{C}$ & 5.57929216 & 0.44031697 & -0.36787907 \\
\hline $\mathrm{C}$ & 6.66866402 & -1.73129642 & -0.46136846 \\
\hline $\mathrm{C}$ & 4.18593288 & 0.90314749 & -0.30582793 \\
\hline $\mathrm{C}$ & 6.79552685 & 1.11159889 & -0.39040998 \\
\hline $\mathrm{C}$ & 7.89831393 & -1.07399709 & -0.49158755 \\
\hline $\mathrm{C}$ & 7.95627831 & 0.33274464 & -0.45043410 \\
\hline $\mathrm{H}$ & 8.82108099 & -1.64064689 & -0.55188693 \\
\hline $\mathrm{N}$ & 3.32404124 & -0.15443677 & -0.29798304 \\
\hline $\mathrm{H}$ & 6.86202237 & 2.19373282 & -0.36546308 \\
\hline $\mathrm{H}$ & -1.39979363 & -5.28130365 & -0.24824837 \\
\hline $\mathrm{H}$ & -3.86538058 & 2.69167776 & -0.01066188 \\
\hline $\mathrm{H}$ & 4.13534510 & 5.19202116 & -0.22118229 \\
\hline $\mathrm{H}$ & 6.61631680 & -2.81516244 & -0.49482316 \\
\hline $\mathrm{C}$ & -0.86545350 & 8.04024879 & -0.35230775 \\
\hline $\mathrm{C}$ & -1.64388472 & 8.73230934 & 0.56848507 \\
\hline $\mathrm{C}$ & -1.39083605 & 7.70330984 & -1.60178911 \\
\hline $\mathrm{C}$ & -2.95479052 & 9.08630124 & 0.23930110 \\
\hline $\mathrm{H}$ & -1.21807479 & 8.99464637 & 1.53196260 \\
\hline $\mathrm{C}$ & -2.70228989 & 8.05530733 & -1.90684332 \\
\hline $\mathrm{H}$ & -0.77716482 & 7.17493667 & -2.32474341 \\
\hline $\mathrm{C}$ & -3.51861584 & 8.75490727 & -0.99968718 \\
\hline $\mathrm{H}$ & -3.53622605 & 9.62824817 & 0.97660290 \\
\hline $\mathrm{H}$ & -3.09137229 & 7.78167818 & -2.88350016 \\
\hline $\mathrm{O}$ & 0.45977828 & 7.78985037 & -0.02375562 \\
\hline $\mathrm{C}$ & -7.50777604 & -0.69632820 & 0.61064081 \\
\hline $\mathrm{C}$ & -7.44773273 & -0.19880549 & 1.91156567 \\
\hline $\mathrm{C}$ & -8.74352742 & -0.84156088 & -0.02163604 \\
\hline $\mathrm{C}$ & -8.62784060 & 0.16101075 & 2.56649792 \\
\hline $\mathrm{H}$ & -6.49020603 & -0.09633829 & 2.41209881 \\
\hline $\mathrm{C}$ & -9.90816971 & -0.48567279 & 0.65163691 \\
\hline
\end{tabular}




\begin{tabular}{|c|c|c|c|}
\hline $\mathrm{H}$ & -8.77518148 & -1.23619507 & -1.03250350 \\
\hline $\mathrm{C}$ & -9.88449824 & 0.02861521 & 1.95994660 \\
\hline $\mathrm{H}$ & -8.54811512 & 0.54457394 & 3.57757570 \\
\hline $\mathrm{H}$ & -10.85673131 & -0.60934227 & 0.13660709 \\
\hline $\mathrm{O}$ & -6.39494417 & -1.14539506 & -0.07717612 \\
\hline $\mathrm{C}$ & 10.31303746 & 0.50536596 & -0.01137767 \\
\hline $\mathrm{C}$ & 10.37821738 & -0.03920384 & 1.27000129 \\
\hline $\mathrm{C}$ & 11.47344156 & 0.62563780 & -0.77633311 \\
\hline $\mathrm{C}$ & 11.60713968 & -0.47200549 & 1.77261030 \\
\hline $\mathrm{H}$ & 9.47899691 & -0.12172049 & 1.87232653 \\
\hline $\mathrm{C}$ & 12.69006546 & 0.19610820 & -0.25378161 \\
\hline $\mathrm{H}$ & 11.40836927 & 1.05793280 & -1.77002760 \\
\hline $\mathrm{C}$ & 12.79165098 & -0.36732390 & 1.03017807 \\
\hline $\mathrm{H}$ & 11.62547228 & -0.89012866 & 2.77290597 \\
\hline $\mathrm{H}$ & 13.57838621 & 0.30092325 & -0.87053350 \\
\hline $\mathrm{O}$ & 9.14510263 & 1.02400014 & -0.54409472 \\
\hline $\mathrm{C}$ & -11.20012538 & 0.41537857 & 2.65992399 \\
\hline $\mathrm{C}$ & -12.11542411 & -0.82792893 & 2.76221576 \\
\hline $\mathrm{H}$ & -13.06208252 & -0.56742829 & 3.25158071 \\
\hline $\mathrm{H}$ & -12.35353514 & -1.24051994 & 1.77612518 \\
\hline $\mathrm{H}$ & -11.63606297 & -1.62013857 & 3.34844837 \\
\hline $\mathrm{C}$ & -11.91881941 & 1.51249495 & 1.83897375 \\
\hline $\mathrm{H}$ & -12.86216756 & 1.79523852 & 2.32217283 \\
\hline $\mathrm{H}$ & -11.29626095 & 2.41072931 & 1.75644811 \\
\hline $\mathrm{H}$ & -12.15341565 & 1.17487907 & 0.82390271 \\
\hline $\mathrm{C}$ & -10.96830865 & 0.95732512 & 4.08306690 \\
\hline $\mathrm{H}$ & -10.48759784 & 0.21438201 & 4.72971388 \\
\hline $\mathrm{H}$ & -10.34856335 & 1.86131579 & 4.08030729 \\
\hline $\mathrm{H}$ & -11.92986080 & 1.21824692 & 4.53938184 \\
\hline $\mathrm{C}$ & -4.96248995 & 9.12040836 & -1.38940452 \\
\hline $\mathrm{C}$ & -5.76260525 & 7.82499928 & -1.66579428 \\
\hline $\mathrm{H}$ & -6.79280831 & 8.06629056 & -1.95503447 \\
\hline $\mathrm{H}$ & -5.31797931 & 7.23750162 & -2.47593472 \\
\hline $\mathrm{H}$ & -5.80021567 & 7.18928950 & -0.77377685 \\
\hline $\mathrm{C}$ & -4.94913762 & 9.99518365 & -2.66554648 \\
\hline $\mathrm{H}$ & -5.97314604 & 10.25802943 & -2.95760653 \\
\hline $\mathrm{H}$ & -4.39367622 & 10.92484896 & -2.49766848 \\
\hline $\mathrm{H}$ & -4.48555614 & 9.47724977 & -3.51167413 \\
\hline $\mathrm{C}$ & -5.68715362 & 9.90516965 & -0.27929555 \\
\hline $\mathrm{H}$ & -5.76189065 & 9.32677907 & 0.64866791 \\
\hline $\mathrm{H}$ & -5.18345330 & 10.85206788 & -0.05363866 \\
\hline $\mathrm{H}$ & -6.70709700 & 10.14279235 & -0.60167554 \\
\hline $\mathrm{C}$ & 14.15930800 & -0.83215138 & 1.56257035 \\
\hline $\mathrm{C}$ & 15.13272912 & 0.36997317 & 1.60221870 \\
\hline $\mathrm{H}$ & 16.11513171 & 0.05520955 & 1.97528829 \\
\hline $\mathrm{H}$ & 15.27933218 & 0.80889071 & 0.60964176 \\
\hline $\mathrm{H}$ & 14.75436374 & 1.15827887 & 2.26288659 \\
\hline $\mathrm{C}$ & 14.73309663 & -1.92426855 & 0.62874666 \\
\hline $\mathrm{H}$ & 15.71546826 & -2.25591523 & 0.98687647 \\
\hline $\mathrm{H}$ & 14.07140896 & -2.79737021 & 0.59392374 \\
\hline
\end{tabular}




$\begin{array}{llll}\mathrm{H} & 14.85847322 & -1.55963091 & -0.39620216 \\ \mathrm{C} & 14.06501422 & -1.41912029 & 2.98382687 \\ \mathrm{H} & 13.69608227 & -0.68223760 & 3.70637239 \\ \mathrm{H} & 13.40742735 & -2.29520676 & 3.02158470 \\ \mathrm{H} & 15.05863161 & -1.73867203 & 3.31743270 \\ \mathrm{C} & -1.66642864 & -7.86331965 & -0.55275435 \\ \mathrm{C} & -2.47944262 & -8.33280597 & 0.47176736 \\ \mathrm{C} & -2.21256786 & -7.55946237 & -1.80100666 \\ \mathrm{C} & -3.84931502 & -8.49503325 & 0.24715198 \\ \mathrm{H} & -2.03772965 & -8.57282490 & 1.43395689 \\ \mathrm{C} & -3.58001389 & -7.72036152 & -2.00356917 \\ \mathrm{H} & -1.56950389 & -7.20464125 & -2.60066712 \\ \mathrm{C} & -4.43407555 & -8.18962331 & -0.98887340 \\ \mathrm{H} & -4.45944116 & -8.86380327 & 1.06380114 \\ \mathrm{H} & -3.98577460 & -7.47792965 & -2.98152766 \\ \mathrm{C} & -5.94030688 & -8.34714027 & -1.26596636 \\ \mathrm{C} & -6.14939492 & -9.34810391 & -2.42719320 \\ \mathrm{H} & -7.21870297 & -9.46534816 & -2.64130573 \\ \mathrm{H} & -5.66077985 & -9.01360838 & -3.34833509 \\ \mathrm{H} & -5.74372632 & -10.33395366 & -2.17273187 \\ \mathrm{C} & -6.70933711 & -8.87107856 & -0.03825656 \\ \mathrm{H} & -6.62934847 & -8.18890405 & 0.81578608 \\ \mathrm{H} & -7.77278869 & -8.96754657 & -0.28403404 \\ \mathrm{H} & -6.35339603 & -9.85876990 & 0.27658927 \\ \mathrm{C} & -6.53745277 & -6.97443814 & -1.65760510 \\ \mathrm{H} & -6.40708323 & -6.24479045 & -0.85045592 \\ \mathrm{H} & -6.06581598 & -6.56428534 & -2.55691684 \\ \mathrm{H} & -7.61139937 & -7.06975735 & -1.85931929 \\ \mathrm{O} & -0.29552043 & -7.78903232 & -0.33295044 \\ \mathrm{H} & 2.20770047 & -7.63399773 & -0.44606603\end{array}$

Figure S1. MALDI-TOF spectra of $\mathrm{tBuH}_{2} \mathrm{Pc}$ positional isomers.

The phthalocyanine structure is highly conjugated and as a result Pc molecules are susceptible to aggregation in highly concentrated solutions. The aggregations causes broadening and overlap of proton NMR peaks making peak assignment difficult. In this work MALD-TOF (and other characterisation techniques) was used to verify the structure and purity of the isomers. The results obtained correlated with previously reported data for a pure $\mathrm{tBuH}_{2} \mathrm{Pc}$ compound (i.e. a mixture of the four isomers). 

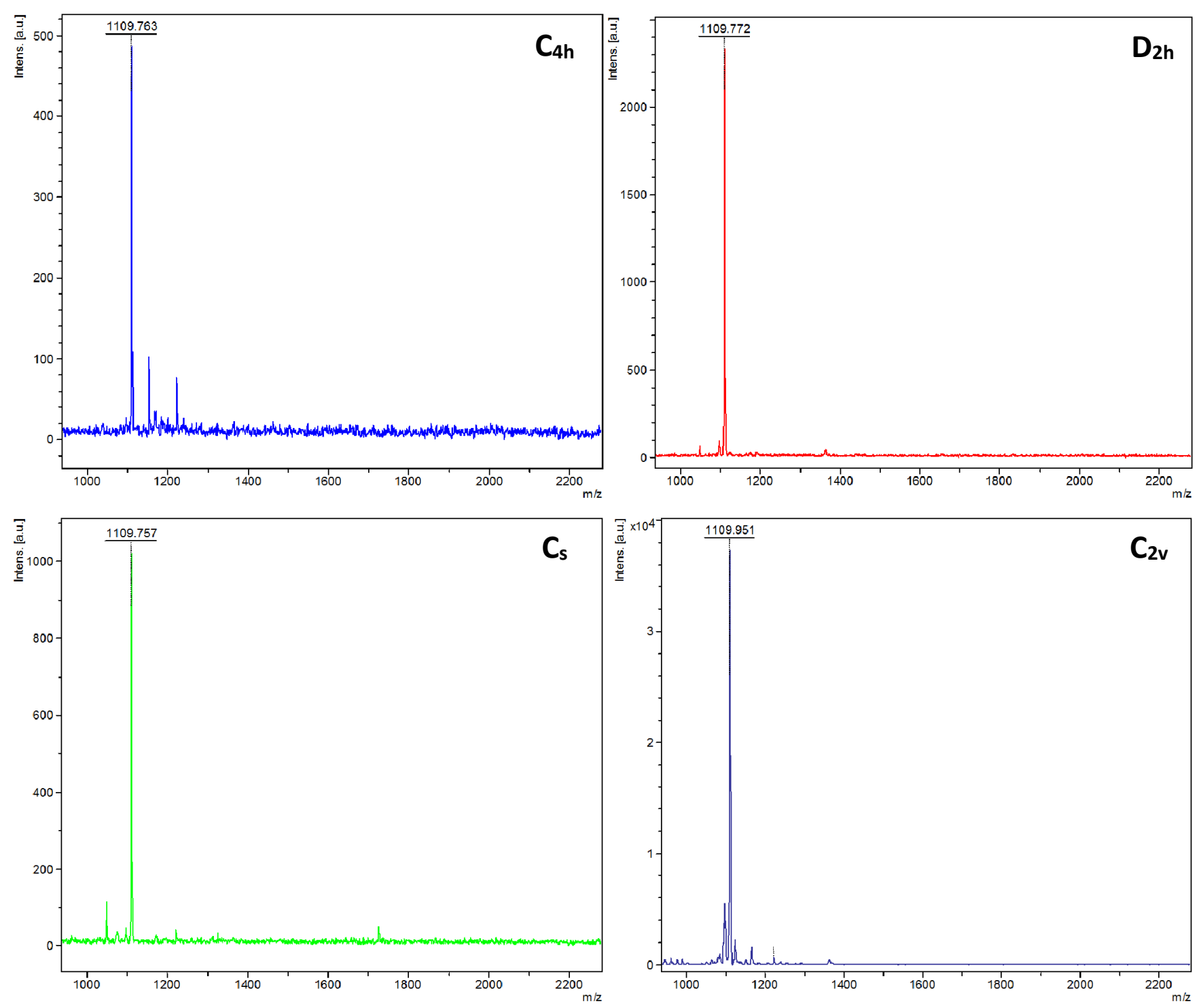

Figure S2. Z-scan (left) and NLO fit (right) for isomers $\mathrm{D}_{2 \mathrm{~h}}, \mathrm{C}_{\mathrm{s}}$ and $\mathrm{C}_{2 \mathrm{v}}$.
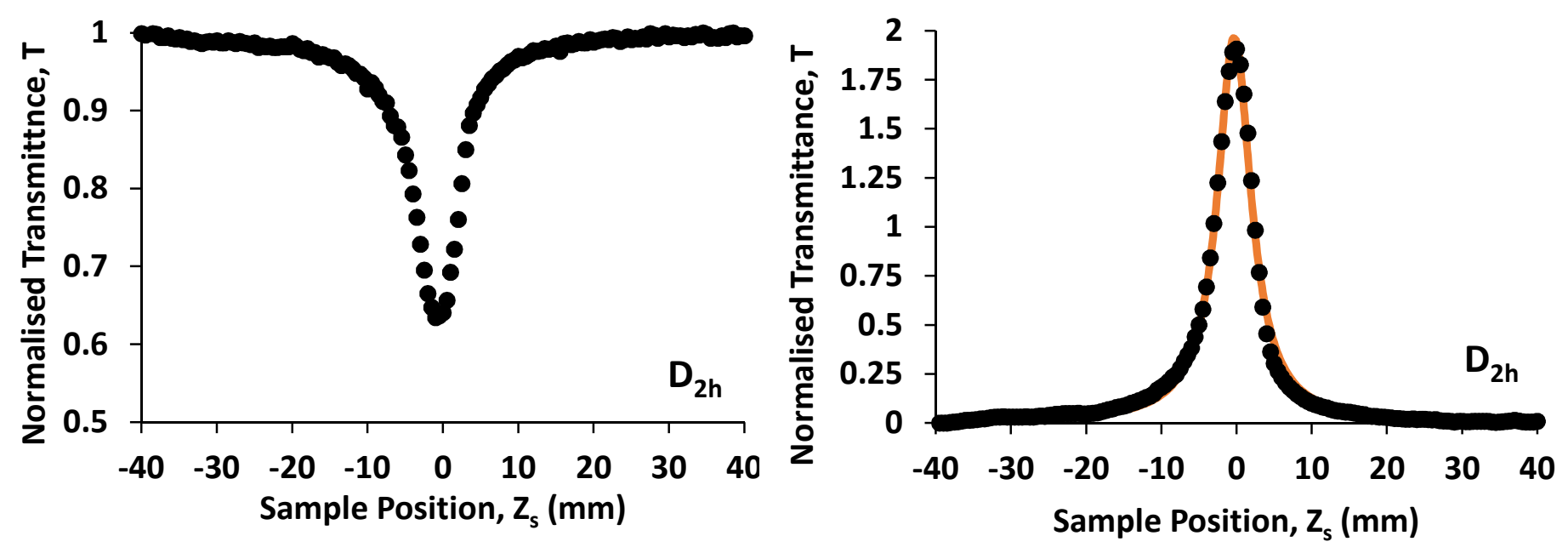

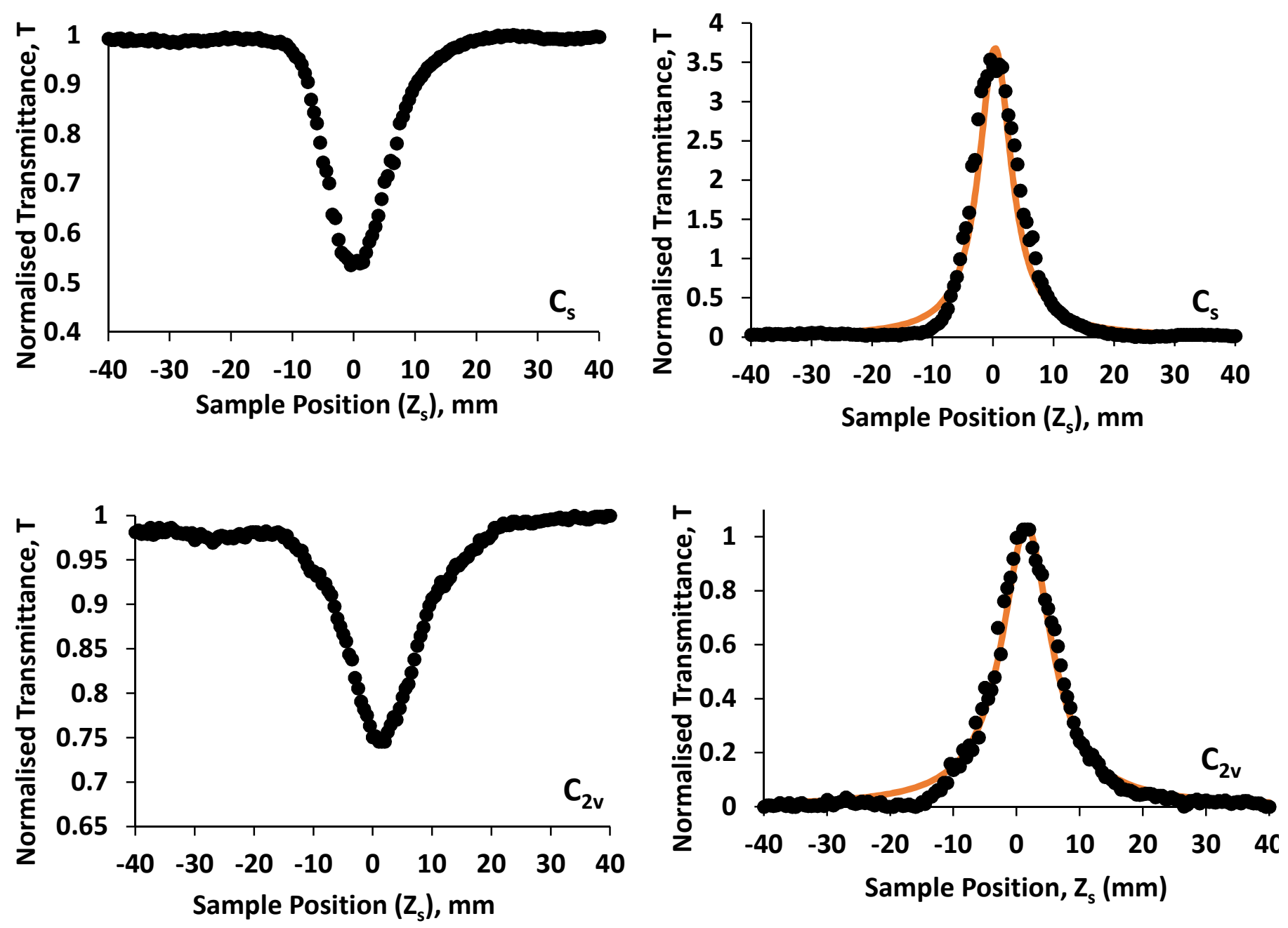

Figure S3. TCSPC trace of the four positional isomers. 

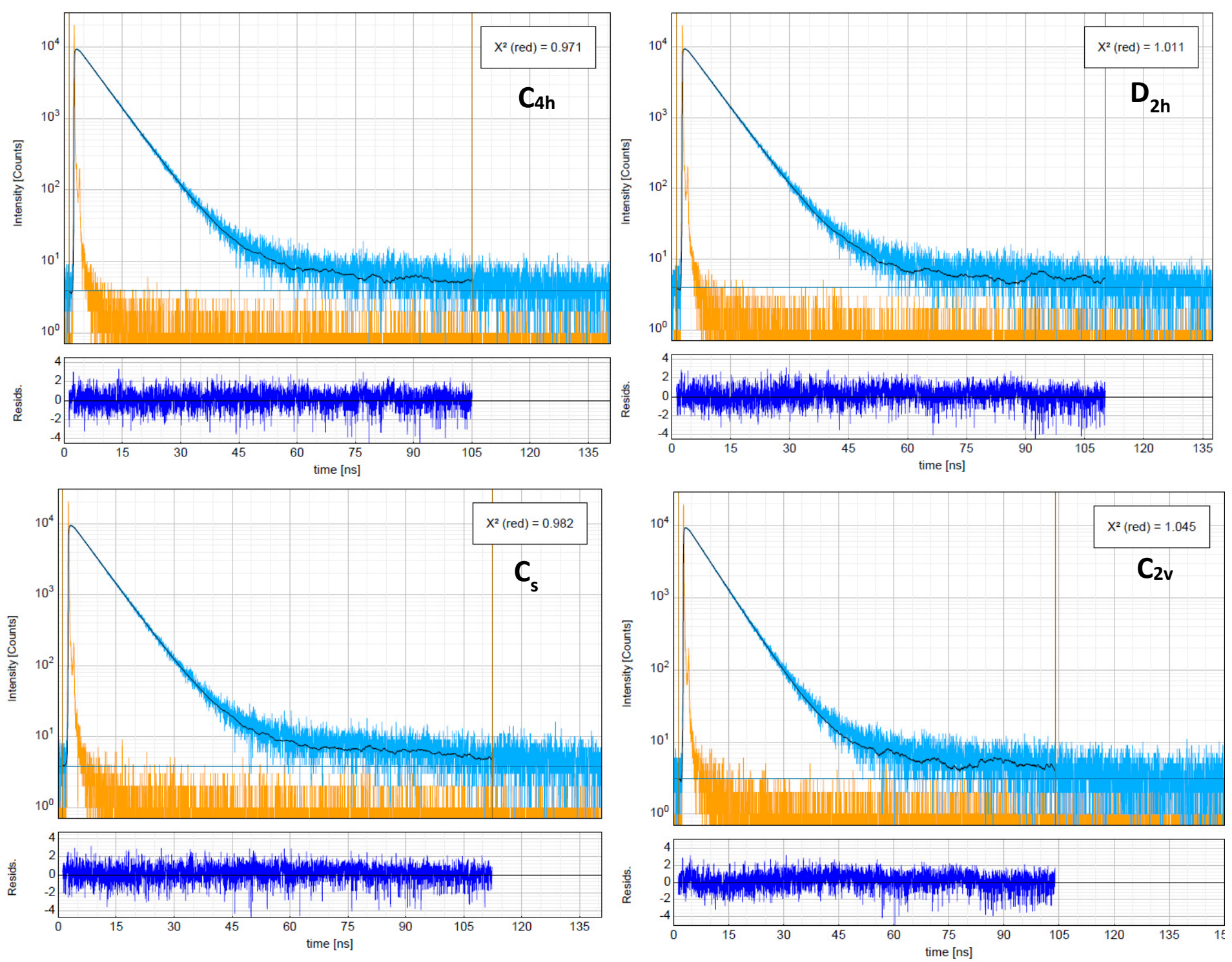

References

1. G. Tsigaridas, I. Polyzos, P. Persephonis and V. Giannetas, A novel approach for analyzing open Z-scan experiments, Opt. Commun, 2006, 266, 284-289.

2. M. Sheik-Bahae, A.A. Said, T.H. Wei, D.J. Hagan and E.W. Van Stryland, Sensitive measurement of optical nonlinearities using a single beam, IEEE J. Quantum Electron, 1990, 26, 760 .

3. M. Kandaz, A.R. Özkaya and Ö. Bekaroğlu, Synthesis and Electrochemistry of Soluble Phthalocyanine Complexes Containing Four Peripheral Dihexyl and Dihexylhexylmalonate Residues, Monatsh. Chem., 2001, 132, 1013-1022. 